RECENPD

FEB 14 isso

OSTI

\title{
EPICS: Allen-Bradley \\ Hardware Reference Manual
}

\author{
Greg Nawrocki
}

\section{DISCLAIMER}

This report was prepared as an account of work sponsored by an agency of the United States Government. Neither the United States Government nor any agency thereof, nor any of their employees, makes any warranty, express or implied, or assumes any legal liability or responsibility for the accuracy, completeness, or usefulness of any information, apparatus, product, or process disclosed, or represents that its use would not infringe privately owned rights. Reference herein to any specific commercial product, process, or service by trade name, trademark, manufacturer, or otherwise does not necessarily constitute or imply its endorsement, recommendation, or favoring by the United States Government or any agency thereof. The views and opinions of authors expressed herein do not necessarily state or reflect those of the United States Government or any agency thereof.

\section{DISTRIBUTION OF THIS DOCUMENT IS UNLIMITED BS}


CHAPTER 1 Allen-Bradley 6008-SV VMEbus I/O Scanner ...... 1

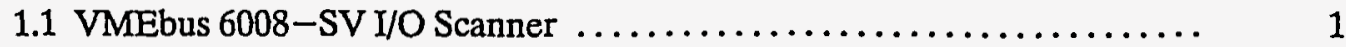

1.2 VMEbus $6008-S V$ I/O Scanner Strapping ........................ 1

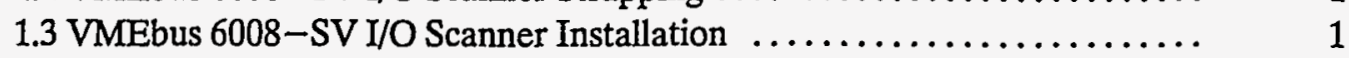

1.3.1 Power Requirements ................................ 1

1.3.2 Module Location in the VME chassis Input Output Controller (IOC) ... 1

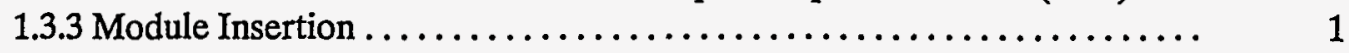

1.4 VMEbus 6008-SV I/O Scanner Wiring Connection ................ 2

1.5 VMEbus $6008-$ SV I/O Scanner Use ........................ 3

\section{CHAPTER 2 Allen-Bradley Universal I/O Chassis}

1771-A1B, -A2B, -A3B, and -A4B ............ 4

2.1 Universal $y / O$ Chassis .................................. 4

2.2 Universal I/O Chassis Strapping $\ldots \ldots \ldots \ldots \ldots \ldots \ldots \ldots \ldots \ldots \ldots \ldots \ldots \ldots \ldots, 4$

2.3 Universal I/O Chassis Module Placement $\ldots \ldots \ldots \ldots \ldots \ldots \ldots \ldots \ldots . .4$

CHAPTER 3 Allen-Bradley Power Supply Module 1771-P4S .... 5

3.1 1771-P4S Power Supply Module ........................... 5

$3.21771-$ P4S Power Supply Module Strapping $\ldots \ldots \ldots \ldots \ldots \ldots \ldots \ldots \ldots . .5$

3.3 1771-P4S Power Supply Module Installation $\ldots \ldots \ldots \ldots \ldots \ldots \ldots \ldots . .6$

3.3.1 Power Requirements ................................. 5

3.3.2 Module Location in the I/O Chassis $\ldots \ldots \ldots \ldots \ldots \ldots \ldots \ldots \ldots \ldots . .6$

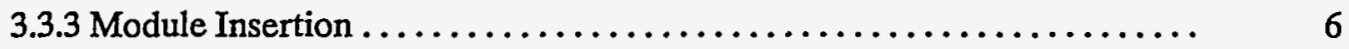

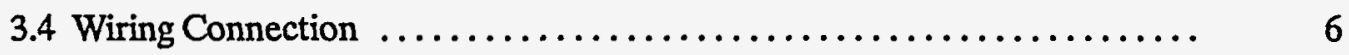

3.4.1 Using Two Power Supply Modules $\ldots \ldots \ldots \ldots \ldots \ldots \ldots \ldots \ldots \ldots \ldots . .6$

$3.51771-$ P4S Power Supply Module Use $\ldots \ldots \ldots \ldots \ldots \ldots \ldots \ldots \ldots \ldots . .6$

CHAPTER 4 Allen-Bradley 1771-ASB Remote I/O Adapter Module 8

4.1 1771-ASB Remote I/O Adapter Module $\ldots \ldots \ldots \ldots \ldots \ldots \ldots \ldots \ldots . .6$

4.2 1771-ASB Remote I/O Adapter Module Configuration .............. 8

4.2.1 Setting the Module Configuration Plug(s) $\ldots \ldots \ldots \ldots \ldots \ldots \ldots \ldots \ldots . .9 . \ldots$

4.2.2 Setting the Module Switches $\ldots \ldots \ldots \ldots \ldots \ldots \ldots \ldots \ldots \ldots \ldots \ldots, \quad 9$

4.2.3 Setting the Universal I/O Chassis backplane switches .............. 10

4.3 1771-ASB Remote I/O Adapter Module Installation ............... 10

4.3.1 Power Requirements .................................. 10

4.3.2 Module Location in the I/O Chassis ....................... 10

4.3.3 Module Keying $\ldots \ldots \ldots \ldots \ldots \ldots \ldots \ldots \ldots \ldots \ldots \ldots \ldots \ldots \ldots \ldots \ldots, 11$

4.3.4 Module Insertion .................................. 11

4.4 1771-ASB Remote I/O Adapter Module Wiring Connection ........... 11

$4.51771-$ ASB Remote I/O Adapter Module Use ................... 12

CHAPTER 5 Allen-Bradley 1771-IFE Analog Input Module ..... 13

$5.11771-$ IFE Analog Input Module ........................... 13

$5.21771-$ IFE Analog Input Module Strapping $\ldots \ldots \ldots \ldots \ldots \ldots \ldots \ldots \ldots \ldots \ldots \ldots \ldots, 13$

5.3 1771-IFE Analog Input Module Installation .................... 14

5.3 .1 Power Requirements ..................................... 14

5.3.2 Module Location in the I/O Chassis ........................ 14

5.3 .3 Module Keying $\ldots \ldots \ldots \ldots \ldots \ldots \ldots \ldots \ldots \ldots \ldots \ldots \ldots \ldots \ldots, 14$

5.3 .4 Module Insertion $\ldots \ldots \ldots \ldots \ldots \ldots \ldots \ldots \ldots \ldots \ldots \ldots \ldots \ldots \ldots \ldots \ldots, 14$

5.41771 -IFE Analog Input Module Wiring Connection .............. 15 
$5.51771-$ IFE Analog Input Module Use $\ldots \ldots \ldots \ldots \ldots \ldots \ldots \ldots \ldots \ldots \ldots$

CHAPTER 6 Allen-Bradley 1771-OFE Analog Output Module .. 16

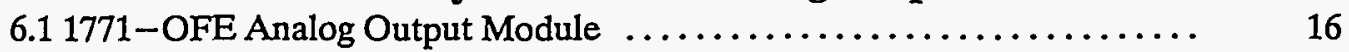

$6.21771-$ OFE Analog Output Module Strapping .................... 16

$6.31771-$ OFE Analog Output Module Installation $\ldots \ldots \ldots \ldots \ldots \ldots \ldots \ldots . \quad 16$

6.3 .1 Power Requirements ................................... $\quad 16$

6.3.2 Module Location in the I/O Chassis ....................... 17

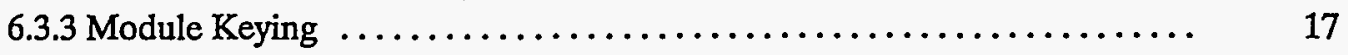

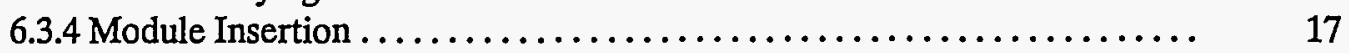

6.4 1771-OFE Analog Output Module Wiring Connection ............. 18

6.5 1771-OFE Analog Output Module Use ....................... 18

CHAPTER 7 Allen-Bradley 1771-IG(D) TTL Input Module ..... 19

7.1 1771-IG(D) TTL Input Module ........................... 19

7.2 1771-IG(D) TTL Input Module Strapping . .................... 19

7.2.1 1771-IG TTL Input Module Strapping ..................... 19

7.2.2 1771-IGD TTL Input Module Strapping ...................... 19

7.3 1771-IG(D) TTL Input Module Installation ................... 20

7.3.1 Power Requirements ................................. 20

7.3.2 Module Location in the I/O Chassis ........................ 20

7.3 .3 Module Keying $\ldots \ldots \ldots \ldots \ldots \ldots \ldots \ldots \ldots \ldots \ldots \ldots \ldots \ldots \ldots \ldots \ldots, \quad 21$

7.3.4 Module Insertion ................................... $\quad 21$

$7.41771-\mathrm{IG}(\mathrm{D})$ TTL Input Module Wiring Connection ............... 21

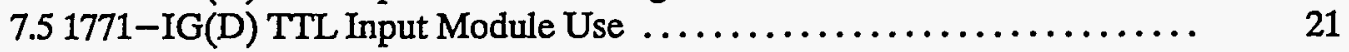

CHAPTER 8 Allen-Bradley 1771-OG(D) TTL Output ......... 23

$8.11771-O G(D)$ TTL Output Module .......................... 23

$8.21771-O G(D)$ TTL Output Module Strapping .................... 23

8.2.1 1771-OG TTL Output Module Strapping $. . . \ldots \ldots \ldots \ldots \ldots \ldots \ldots \ldots . .23$

$8.2 .21771-O G D$ TTL Output Module Strapping ...................... 23

$8.31771-O G(D)$ TTL Output Module Installation $. . \ldots \ldots \ldots \ldots \ldots \ldots \ldots . .24$

8.3.1 Power Requirements .................................. 24

8.3.2 Module Location in the I/O Chassis .......................... 24

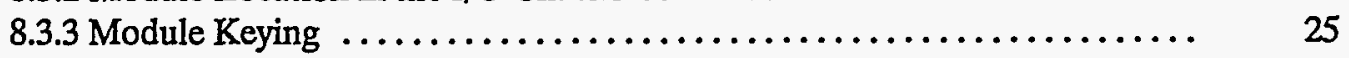

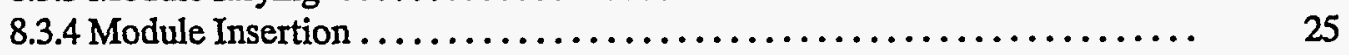

$8.41771-O G(D)$ TTL Output Module Wiring Connection ................ 25

$8.51771-$ OG(D) TTL Output Module Use ....................... 25

CHAPTER 9 Allen-Bradley 1771-IQ DC Selectable Input Module 27

$9.11771-$ IQ DC Selectable Input Module ....................... 27

$9.21771-$ IQ DC Selectable Input Module Strapping ................. 27

9.3 1771-IQ DC Selectable Input Module Installation ................. 27

9.3.1 Power Requirements .................................. 27

9.3.2 Module Location in the $\mathrm{I} / \mathrm{O}$ Chassis $\ldots \ldots \ldots \ldots \ldots \ldots \ldots \ldots \ldots \ldots . .27$

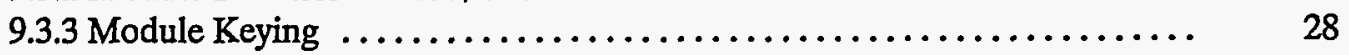

9.3.4 Module Insertion ................................... 28

9.4 1771-IQ DC Selectable Input Module Wiring Connection ................ 29

$9.51771-$ IQ DC Selectable Input Module Use ..................... 29

CHAPTER 10 Allen-Bradley 1771-OW Contact Output Module . 30

10.1 1771-OW Contact Output Module .......................... 30 
10.2 1771-OW Contact Output Module Strapping ................. 30

$10.31771-$ OW Contact Output Module Installation $\ldots \ldots \ldots \ldots \ldots \ldots \ldots . . . \ldots \ldots \ldots \ldots \ldots$

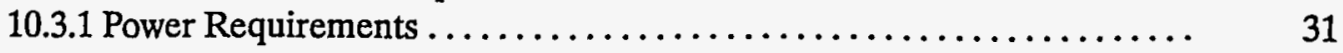

10.3.2 Module Location in the I/O Chassis $\ldots \ldots \ldots \ldots \ldots \ldots \ldots \ldots \ldots . . . \ldots \ldots$

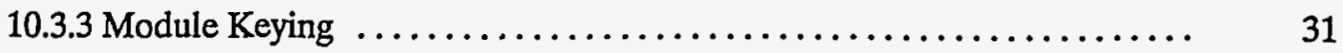

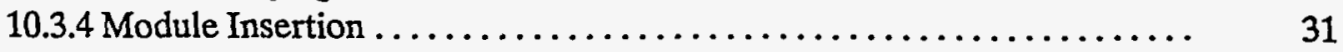

10.41771 -OW Contact Output Module Wiring Connection ............. 31

10.51771 -OW Contact Output Module Use ................... 32

CHAPTER 11 Allen-Bradley 1771-IBD DC (10-30V)

Input Module .......................... 33

$11.11771-$ IBD DC $(10-30 \mathrm{~V})$ Input Module $\ldots \ldots \ldots \ldots \ldots \ldots \ldots \ldots . \ldots \ldots \ldots$

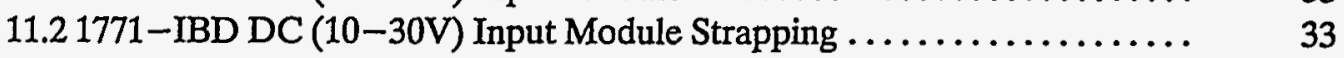

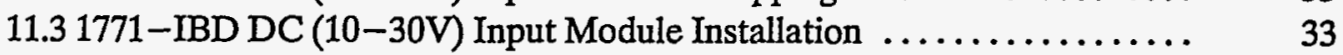

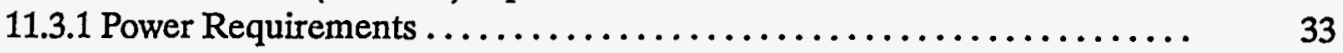

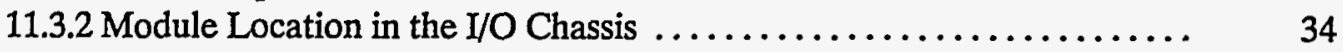

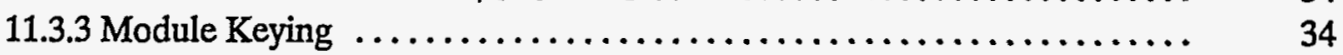

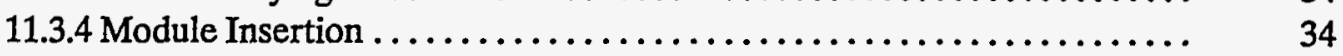

$11.41771-$ IBD DC $(10-30 \mathrm{~V})$ Input Module Wiring Connection ........... 34

$11.51771-\mathrm{IBD}$ DC $(10-30 \mathrm{~V})$ Input Module Use .................. 35

CHAPTER 12 Allen-Bradley 1771-OBD DC (10-60V)

Output Module ........................... 36

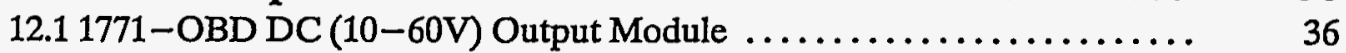

$12.21771-$ OBD DC $(10-60 \mathrm{~V})$ Output Module Strapping $\ldots \ldots \ldots \ldots \ldots \ldots . . \ldots \ldots \ldots \ldots \ldots$

$12.31771-\mathrm{OBD}$ DC $(10-60 \mathrm{~V})$ Output Module Installation ............. 36

12.3.1 Power Requirements ............................... 36

12.3.2 Module Location in the I/O Chassis ..................... 37

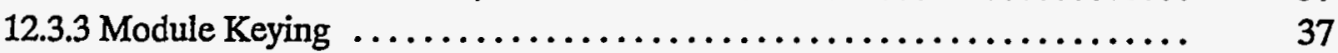

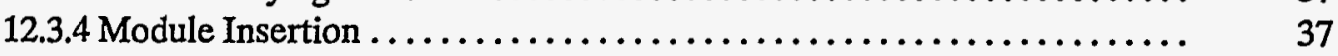

$12.41771-O B D$ DC $(10-60 \mathrm{~V})$ Output Module Wiring Connection ......... 37

$12.51771-$ OBD DC (10-60V) Output Module Use ................ 38

CHAPTER 13 Allen-Bradley 1771-IXE Thermocouple / Millivolt Input Module ...........................

13.1 1771-IXE Thermocouple / Millivolt Input Module ............... 39

13.2 1771-IXE Thermocouple / Millivolt Input Module Strapping ......... 39

13.3 1771-IXE Thermocouple / Millivolt Input Module Installation ........ 39

13.3.1 Power Requirements .................................. 39

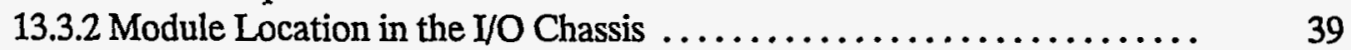

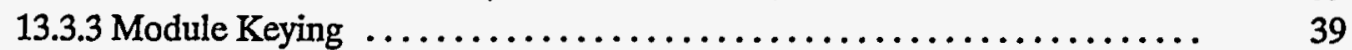

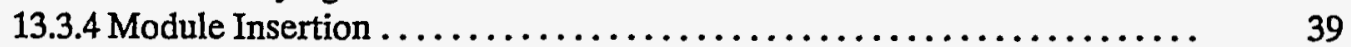

13.4 1771-IXE Thermocouple / Millivolt Input Module Wiring Connection .. 40

13.5 1771-IXE Thermocouple/Millivolt Input Module Use ............. 41

CHAPTER 14 Allen-Bradley 2705 RediPANEL Push Button Module 42

14.1 RediPANEL Push Button Module ......................... 42

14.2 RediPANEL Push Button Module Configuration $\ldots \ldots \ldots \ldots \ldots \ldots \ldots . \ldots . \ldots . \ldots . \ldots$

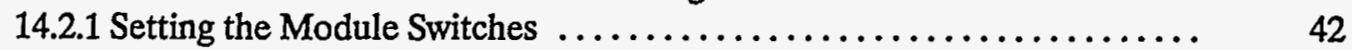

14.3 RediPANEL Push Button Module Installation ................... 44

14.3.1 Power Requirements ............................... 44 


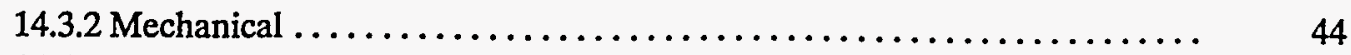

14.4 RediPANEL Push Button Module Wiring Connection ............... 44

14.5 RediPANEL Push Button Module Module Use .................. 44

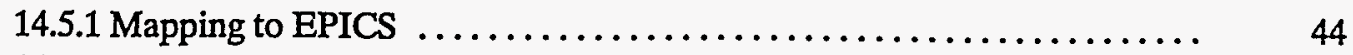

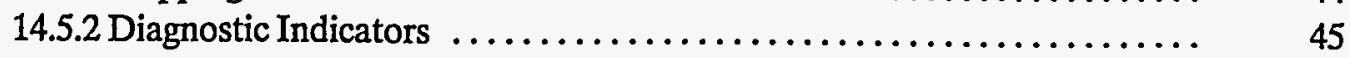

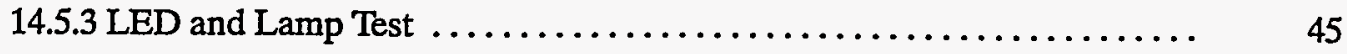




\section{CHAPTER 1 Allen-Bradley 6008-SV VMEbus I/O Scanner}

\subsection{VMEbus 6008-SV I/O Scanner}

The VMEbus I/O Scanner physically resides in a VME chassis Input Output Controller (IOC), and acts as a master for an Allen Bradley subnet in an EPICS control system. The address of the VMEbus I/O Scanner corresponds to the LINK number in an Allen-Bradley / EPICS subnet. Up to two VMEbus I/O Scanners (LINK 0 and LINK 1) may be used in one VME chassis IOC. In an EPICS control system, one VMEbus I/O Scanner has the ability to be the master for up to 8 Allen Bradley slave nodes, including Remote I/O Adapters in Allen Bradley 1771 Series I/O Chassis, or Allen Bradley RediPANEL Pushbutton Modules, both commonly used in an EPICS control system. In an Allen-Bradley / EPICS subnet the addresses of the slave nodes are referred to as the ADAPTER number.

\subsection{VMEbus 6008-SV I/O Scanner Strapping}

Refer to figure 1.1 when strapping the VMEbus I/O Scanner. J2, J6, J7, and J8 are factory mandated settings and should not be altered from their illustrated positions. J1, J4, and positions $1-4$ of J5 are set as illustrated so that the VMEbus I/O scanner conforms to standard 24 bit supervisory access data addressing, the mode used in an EPICS control system. J3, and positions 5-8 of J5 are set for the proper base address of a VMEbus I/O scanner in an EPICS control system. They should be inserted as illustrated in figure 1.1 with the exception of J5 position 8. This jumper should be inserted for a VMEbus I/O scanner module used as LINK $\mathbf{0}$, and removed for a VMEbus I/O scanner module used as LINK 1.

\subsection{VMEbus 6008-SV I/O Scanner Installation}

\subsubsection{Power Requirements}

The Allen-Bradley VMEbus I/O Scanner may be installed in any VME chassis IOC. Before Installation, calculate the power requirements of the modules currently in the VME chassis IOC. Add to that 2.5A @ 5V DC, the current required by the VMEbus I/O Scanner. Check to be sure that this combined current requirement does not exceed the current driving ability of the VME chassis IOC power supply.

\subsubsection{Module Location in the VME chassis Input Output Controller (IOC)}

The VMEbus I/O Scanner is a $6 U$, double height VME board which may occupy any slot but the first slot in a VME chassis IOC, this slot is commonly occupied by the VME processor module.

\subsubsection{Module Insertion}

Before a module is inserted into a VME chassis IOC, be sure that the power to the IOC is shut off. As always, be sure that "bringing down" this specific IOC will not have detrimental effects on any part of the control system serviced by this particular IOC. To insert the module, place it in the plastic tracks on the top and bottom of the VME chassis IOC. Slide the module into the IOC until the module comes in contact with the backplane connectors. Do 
Figure 1.1

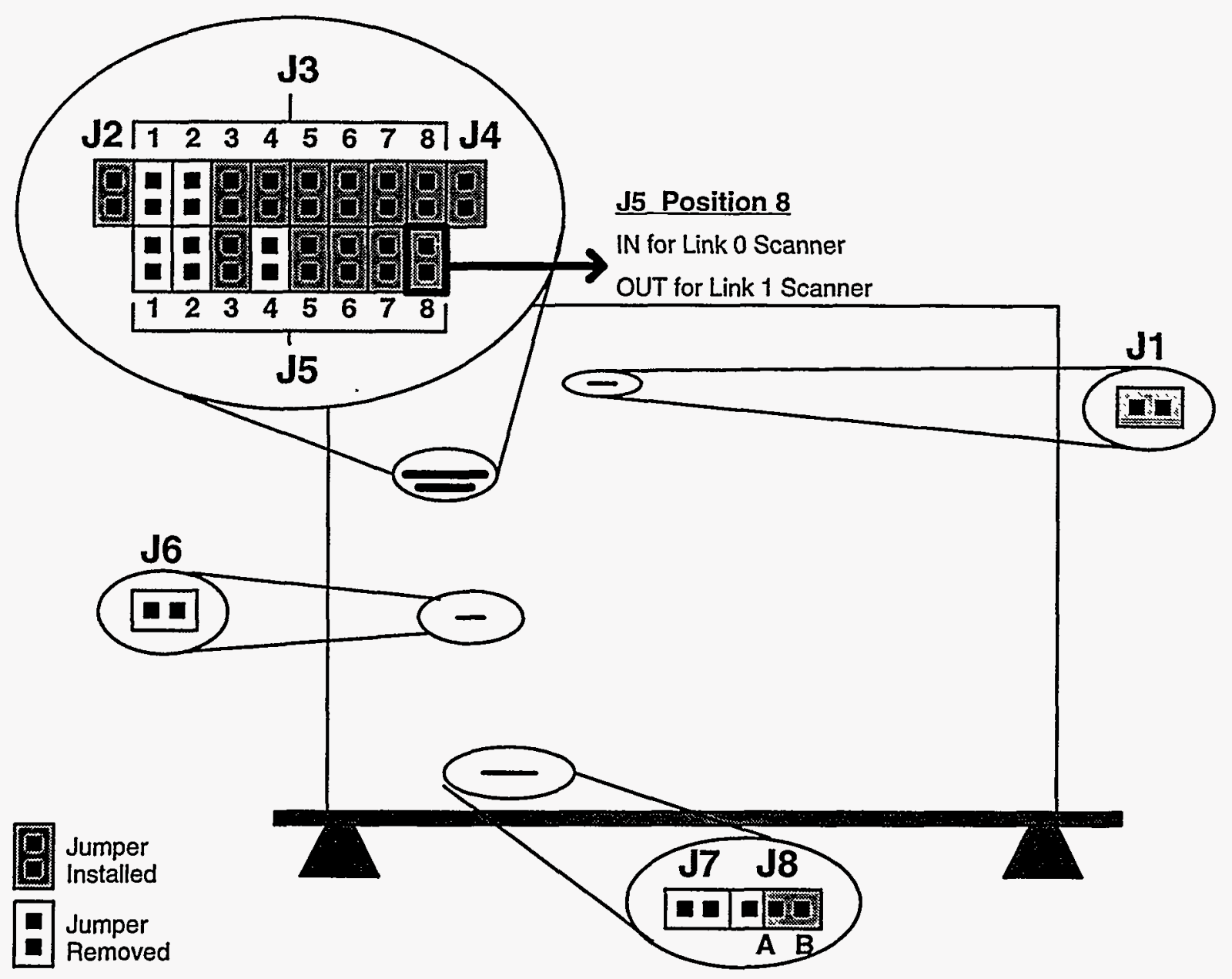

not force the module in, instead apply firm and even pressure on the module to seat it properly on the backplane connectors. Tighten the screws at the top and bottom of the face panel of the VMEbus I/O Scanner (be sure not to over-tighten) so that the I/O Scanner remains firmly in place in the VME chassis IOC.

\subsection{VMEbus 6008-SV I/O Scanner Wiring Connection}

Connection between the VMEbus I/O Scanner master, and the Allen-Bradley subnet slave modules such as the remote $I / O$ adapters or RediPANELs should be made via shielded twinaxial cable. The use of Belden 9463 J22 304.8MTR BLUSTG is recommended. This cable has the following specifications.

78 OHM TWINAXIAL CABLE

2 CONDUCTOR

20 AWG (.52 sq. mm) 7x\#28 (.08 sq. mm) Tinned $\mathrm{Cu}$

$.0185 "(.47 \mathrm{~mm})$ SOLID PE DIALECTRIC

BELDFOIL 100\% + Tinned Cu BRAID 57\% 
.032" (81mm) PVC JACKET - .243" O.D.

SURFACE PRINTED

(UL) TYPE CM

USE: COMMUNICATION CIRCUITS IN ACCORDANCE WITH NEC ARTICLE 800 AWM STYLE 2582

$60 \mathrm{C} 150 \mathrm{~V}$

The VMEbus I/O Scanner should be used with the supplied connector that fits into JK1 of the VMEbus I/O Scanner. The wires should be inserted into the connector so that the corresponding connection to JK1 will appear as in figure 1.2.

\section{Figure 1.2}

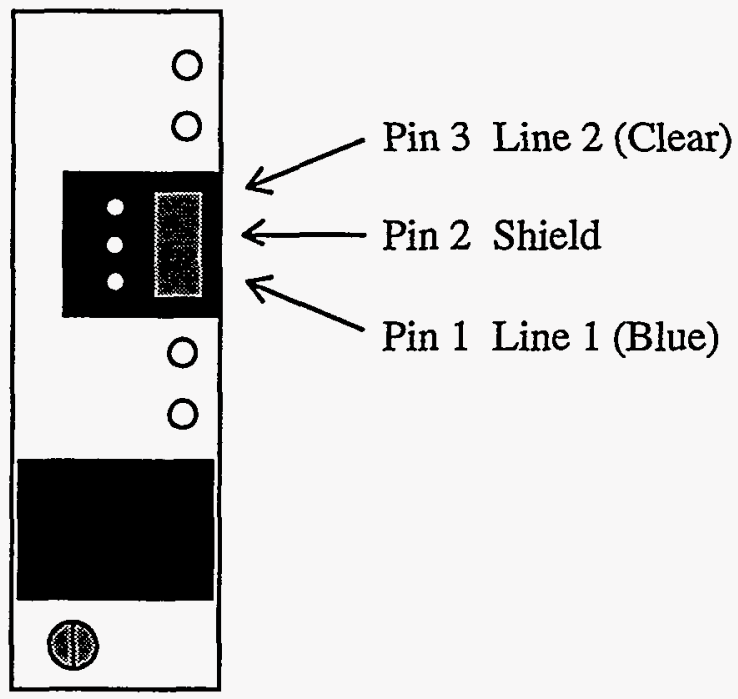

This diagram represents the bottom of the VMEbus I/O Scanner VME module.

\subsection{VMEbus 6008-SV I/O Scanner Use}

The front panel of the VMEbus I/O scanner contains four LEDs which indicate the status of the I/O Scanner. The PWR (power) LED is lighted green when power (5V) is applied to the module through the VME backplane. The SER COM (serial communication) LED is lighted solid green when the scanner is able to communicate with all of its slaves, flashes green when able to communicate with some of its slaves, and is out when unable to communicate with any of its slaves. The BPLN COM (backplane communication) LED lights green for half a second when a VMEbus access is made to the VMEbus I/O Scanner. The FLT (fault) LED lights red when the VMEbus I/O scanner is reset, performing a self test, or a fault has been detected. 


\section{CHAPTER 2 Allen-Bradley Universal I/O Chassis 1771-A1B, $-\mathrm{A} 2 \mathrm{~B},-\mathrm{A3B}$, and $-\mathrm{A} 4 \mathrm{~B}$}

\subsection{Universal I/O Chassis}

The Allen-Bradley Universal I/O Chassis provide backplane connections for the 1771 series I/O modules, a 1771-ASB Remote I/O Adapter Module, and a combination of 1771 power supply modules. The chassis come in four sizes, the $-\mathrm{A} 1 \mathrm{~B}$ chassis has 4 slots, the $-\mathrm{A} 2 \mathrm{~B}$ chassis has 8 slots, the $-\mathrm{A} 3 \mathrm{~B}$ has 12 slots, and the $-\mathrm{A} 4 \mathrm{~B}$ has 16 slots.

\subsection{Universal I/O Chassis Strapping}

The Universal I/O Chassis contains a backplane switch assembly located on the left hand, lower side of the backplane as you look into the chassis. Refer the the section on the AllenBradley 1771-ASB Remote I/O Adapter Module for instructions on the setting of these switches. There is also a power supply configuration jumper located along the top of the backplane as you look into the chassis. This jumper should be set to the right position if an external power supply is used, and set to the left position (most common in an EPICS control system) if a power supply module such as the 1771-P4S Power Supply Module is used.

\subsection{Universal I/O Chassis Module Placement}

The Allen-Bradley 1771-ASB Remote I/O Adapter Module must reside in the left most slot of the I/O chassis. Other restrictions to 1771 series module placement may apply, these will be mentioned on a per-module basis. 


\section{CHAPTER 3 Allen-Bradley Power Supply Module 1771-P4S}

\subsection{1-P4S Power Supply Module}

The 1771-P4S Power Supply Module is a 5V, 8A power supply that can be used in the 1771-A1B, -A2B, -A3B, and -A4B Universal I/O Chassis. Up to two of these supplies may be used as dictated by the power requirements of the 1771 series $\mathrm{I} / \mathrm{O}$ modules contained in the Universal I/O Chassis. If two supplies are used, they must be connected by a Power Supply Paralleling Cable.

\subsection{1-P4S Power Supply Module Strapping}

Place the module so that the right hand cover plate (the one with the labels) is facing down on a flat surface, and the front of the module is facing away from you. The module should appear as it does in figure 3.1 with the two configuration jumpers just behind the gold connecting traces of the circuit board. These jumpers select the proper voltage regulation for the different power supply configurations. The right position (rarely used in an EPICS control system) selects the configuration for a single power supply in a power supply chassis, connected to an I/O chassis through a power supply cable. In an EPICS control system, they should be configured as they appear in figure 3.1, with both of the jumpers located on the left hand side of the three pin headers.

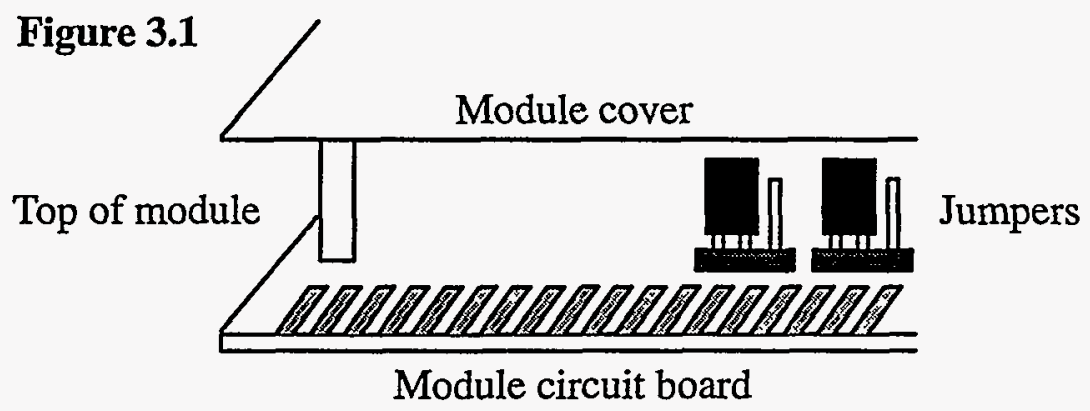

\subsection{1-P4S Power Supply Module Installation}

\subsubsection{Power Requirements}

The Allen-Bradley 1771-P4S Power Supply Module may be installed in any Allen-Bradley Universal I/O Chassis, 1771-A1B, 1771-A2B, 1771-A3B, or 1771-A4B. Each module supplies a maximum of $8 \mathrm{~A}$ to the other modules in the $\mathrm{V} / \mathrm{O}$ crate. Two of these modules may be used per I/O chassis to supply a maximum of $16 \mathrm{~A}$ to the other modules in the chassis. Adding the current requirements of all of the modules in the $\mathrm{I} / \mathrm{O}$ chassis will indicate if two power supply modules are needed, or if one will suffice.

The Allen-Bradley 1771-P4S Power Supply Module itself requires $120 \mathrm{~V}$ AC (actual voltage input range is $97-132 \mathrm{VAC} \mathrm{rms)}$ ) at a frequency of $47-63 \mathrm{~Hz}$. The module is protected with a $1.5 \mathrm{~A} 250 \mathrm{~V}$ Slow-blow fuse located on the front panel. 


\subsubsection{Module Location in the I/O Chassis}

The Allen-Bradley 1771-P4S Power Supply Module may be placed in any slot of the I/O chassis with the exception of of the extreme left slot. This slot is occupied by the Remote I/O Adapter Module. It is suggested that the power supply modules be placed away from analog input modules and low voltage DC modules to minimize electrical noise interference.

\subsubsection{Module Insertion}

Before a power supply module is inserted into the Universal I/O Chassis, be sure that the power switch is in the off position, and that the 120VAC cable is disconnected from the module. If a Remote $\mathrm{I} / \mathrm{O}$ Adapter is currently in the Universal I/O Chassis, this procedure can be done without shutting off the IOC that the Universal I/O Chassis is connected to, and without removing the subnet communication link. To insert the module, place it in the plastic tracks on the top and bottom of the Universal I/O Chassis. Slide the module into the Universal I/O Chassis until the module comes in contact with the backplane connector. Do not force the module in, instead apply firm and even pressure on the module to seat it properly on the backplane connector. Snap the chassis latch over the top of the module and connect the 120VAC connector to the module. The Universal I/O Chassis should begin communicating with the host IOC when the power is switched on, no rebooting of the IOC will have to be done.

\subsection{Wiring Connection}

Connection of the 120VAC power to the 1771-P4S is accomplished through the use of a Wago 231-205/000-008 connector (Allen-Bradley part number 941274-05) included with each 1771-P4S. Figure 3.2 illustrates how the 120VAC power should be connected to the 1771-P4S modules. Note that two modules are illustrated in figure 3.2, only one power supply module may be needed depending upon the current requirements of the modules in the Universal I/O Chassis.

\subsubsection{Using Two Power Supply Modules}

If two power supply modules are used in one Universal I/O Chassis they must be linked together through the Power Supply Paralleling Cable, Allen-Bradley part number 1771-CT. This connection is a communication link between the two supplies. If one of the supplies has to shut down, it informs the second supply to turn off its P/S ACTIVE indicator. If this shut down procedure does occur, the Remote I/O Adapter will be disabled, however, the second supply will continue to supply power until its DC output limits are exceeded. Because the Remote I/O Adapter will be disabled if either of two power supply modules shut down, placing two power supplies in one Universal I/O Chassis does not provide redundancy. The Power Supply Paralleling Cable should be looped over the top of the I/O chassis to avoid picking up signals induced from the $\mathrm{I} / \mathrm{O}$ wiring.

\subsection{1-P4S Power Supply Module Use}

The 1771-P4S is used by simply turning on the power switch located on the front of the mod-' ule. If two supplies are being used, turn them on simultaneously, otherwise the first supply powered on may shut down due to an over-current condition. Remember to shut the supply, or supplies down when inserting or removing any module from the Universal I/O Chassis. 
Figure 3.2

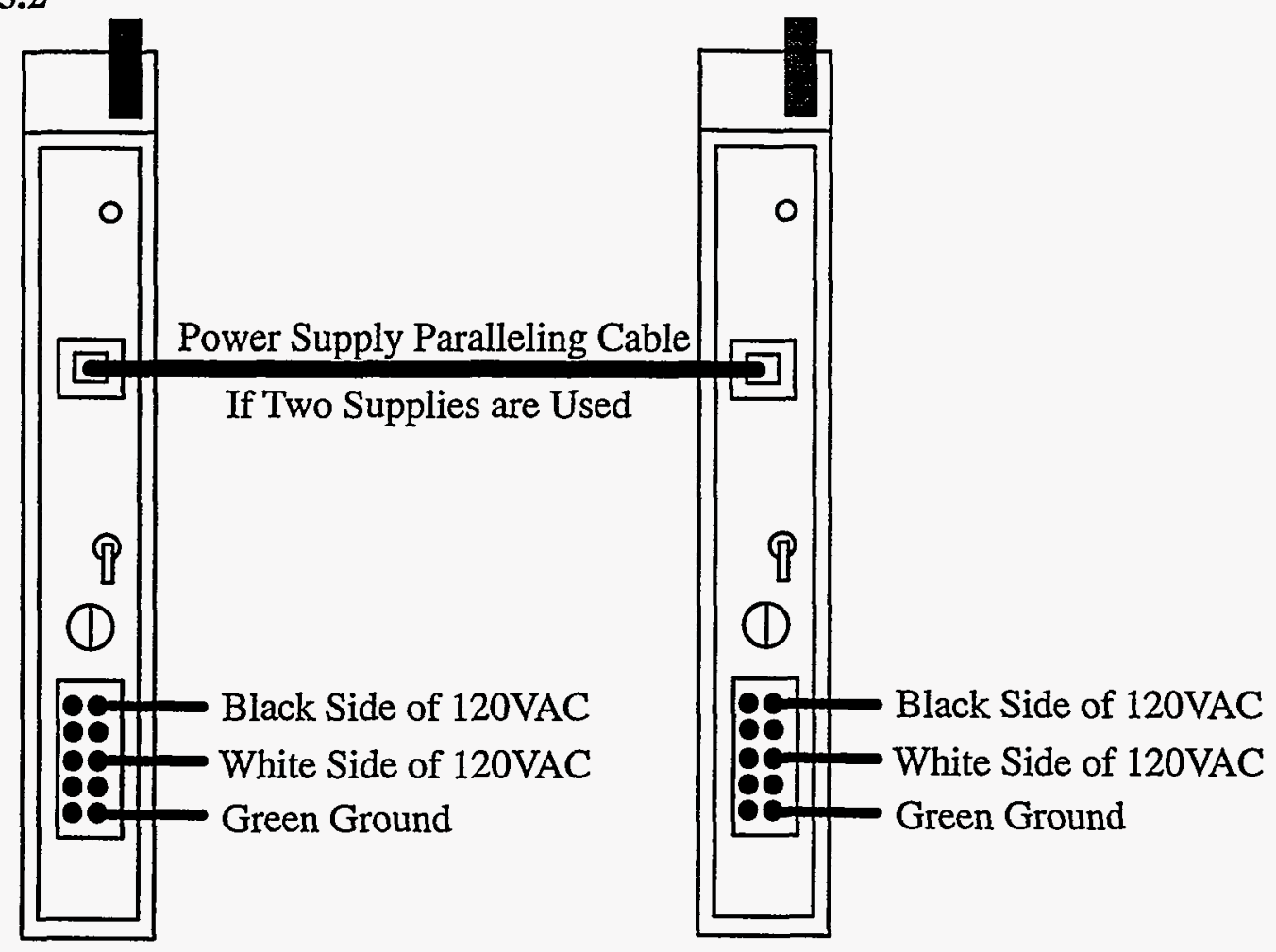

The front of the 1771-P4S contains a P/S ACTIVE (power supply active) indicator. If the indicator is illuminated green, the power supply, and any supply connected to it through a power supply paralleling cable is operating normally. Note that this does not guarantee that the power supply is correctly inserted and supplying power to the backplane. If the indicator is off the power supply module has detected one of the following conditions: DC over-voltage, DC under-voltage, DC over-current, power switch turned off, AC under-voltage, or that any power supply module connected to it through a power supply paralleling cable has detected a similar condition. 


\section{CHAPTER 4 Allen-Bradley 1771-ASB Remote I/O Adapter Module}

\subsection{1-ASB Remote I/O Adapter Module}

The Allen-Bradley 1771-ASB Remote I/O Adapter Module physically resides in a Universal $\mathrm{I} / \mathrm{O}$ Chassis, and acts as a slave in an Allen Bradley subnet in an EPICS control system. The 1771-ASB Remote I/O Adapters are linked via subnet connection to other Remote I/O Adapters in Allen Bradley 1771 Series I/O Chassis, Allen-Bradley RediPANEL Pushbutton Modules, and back to a VMEbus I/O scanner. They correspond to the ADAPTER number when configuring an Allen-Bradley subnet. An Allen-Bradley / EPICS subnet allows for up to 8 adapters to be located on one Allen-Bradley subnet link.

\subsection{1-ASB Remote I/O Adapter Module Configuration}

Refer to figure 4.1 for the following instructions. There are three steps involved in the configuration of a 1771-ASB Remote I/O Adapter Module, the first involves the setting of the Module Configuration Plug or Plugs, the second involves the setting of the Module Switches, and the third involves the setting of the Universal I/O Chassis backplane switches located on the left hand, lower side of the backplane as you look into the chassis. Note that there are two styles of Remote I/O Adapter, they are easily discerned by looking at SW 2. In the older style module SW 2 is a 4 position DIP switch, in the newer style, SW 2 is a 6 position DIP switch.

\section{Figure 4.1}

Older Style Remote I/O Adapter

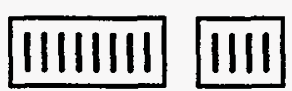

SW 1 SW 2

Module Configuration Plug

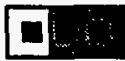

Newer Syle Remote I/O Adapter

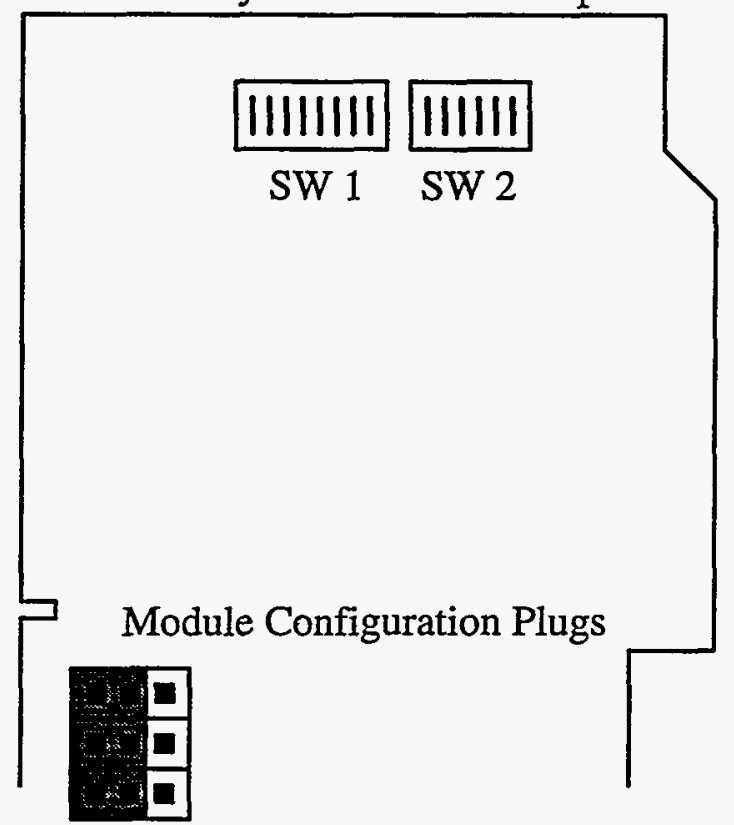




\subsubsection{Setting the Module Configuration Plug(s)}

If you have the older style Remote I/O Adapter begin by laying the module on its right side (label side down). Remove the left cover by removing the 4 screws. Locate the configuration plug and place the jumper in the right most position as indicated in figure 4.1. Replace the cover and secure the 4 screws.

If you have the newer style Remote I/O Adapter, access to the Module Configuration Plugs can be gained through a small access hole in the lower left corner of the left cover of the module. Place all three jumpers in the left most position as indicated in figure 4.1.

In either of the above cases the Remote I/O Adapter module is placed in a mode for use with 32-point I/O modules and any address method. This is the configuration used in an EPICS control system. Note that in this mode you may not use the 1771-IX or the 1771-IY modules.

\subsubsection{Setting the Module Switches}

$\mathrm{S} 1$ is the Address Switch Assembly in both the newer and older style Remote $\mathrm{I} / \mathrm{O}$ adapters. Switches $1-6$ select the Universal $\mathrm{I} / \mathrm{O}$ Chassis adapter number. Observe figure 4.2 for the proper address settings, when the switches are closed $(\mathrm{ON})$ this corresponds to a binary 0 in the adapter address, and when the switches are open (OFF) this corresponds to a binary 1 in the adapter address. Note that switches $1-3$ must always remain in their closed (ON) positions as the EPICS control system only uses adapter addresses $0-7$.

Figure 4.2 \begin{tabular}{|c|c|c|c|}
\hline I/O Adapter & \multicolumn{3}{|c|}{ Switch Number } \\
Number & 4 & 5 & 6 \\
\hline 0 & On & On & On \\
\hline 1 & On & On & Off \\
\hline 2 & On & Off & On \\
\hline 3 & On & Off & Off \\
\hline 4 & Off & On & On \\
\hline 5 & Off & On & Off \\
\hline 6 & Off & Off & On \\
\hline 7 & Off & Off & Off \\
\hline
\end{tabular}

Switches 7 and 8 should remain in the closed (ON) position as this will place the Remote $\mathrm{I} / \mathrm{O}$ adapter in the 1st I/O group number 0, used in the EPICS control system.

S2 sets the baud rate and other configurations. For both the older and newer style of Remote I/O Adapter switch number 1 should be closed (ON), and switch number 2 should be open (OFF) this sets the baud rate at $57.6 \mathrm{~K}$ baud and allows for a link distance of $10,000 \mathrm{ft}$ over twisted pair cable. This is the preferred setting for an EPICS control system. Switch number 3 should remain open (OFF) as it is not used, and switch number 4 should remain open (OFF) to put the Remote $\mathrm{I} / \mathrm{O}$ adapter in scanning mode for all slots. 
If you have the newer style Remote I/O Adapter switch number 5 should be open (OFF) for unrestricted emulation, and switch number 6 should be open (OFF) as it is not used. A summary of switch positions is available in figure 4.3 .

Figure 4.3

\begin{tabular}{|c|c|c|c|c|c|c|c|c|c|c|c|c|}
\hline \multicolumn{7}{|c|}{ S1 Switch Number } & \multicolumn{5}{|c|}{ S2 Switch Number } \\
\hline 1 & 2 & 3 & 4 & 5 & 6 & 7 & 1 & 2 & 3 & 4 & 5 \\
\hline On & On & On & Figure 4.2 & On & On & On & Off & Off & Off & Off & Off \\
\hline
\end{tabular}

On $=$ Closed

Off $=$ Open

Ignore S2-5 and S2-6 for older style Remote I/O Adapter

\subsubsection{Setting the Universal I/O Chassis backplane switches}

The Allen-Bradley Universal I/O Chassis contains a backplane switch assembly located on the left hand, lower side of the backplane as you look into the chassis. The switches are labeled $1-8$, with switch 1 on the top, and switch 8 on the bottom.

Switch 1 is the Last State Switch. When closed (ON) outputs from the chassis will remain in the last state when a fault is detected. When open (OFF) the outputs will be de-energized when a fault is detected. The common EPICS setting for this switch is closed (ON).

Switch 2 is the Processor Restart Switch. When closed (ON) the processor has the ability to restart the chassis. When open (OFF) the chassis must be restarted at the chassis. The common EPICS setting for this switch is closed (ON).

Switch 3 and Switch 4 are not used, and should always remain open (OFF).

Switch 5 and Switch 6 should always remain open (OFF) to select 2 slot addressing.

Switch 7 is not used, and should always remain open (OFF).

Switch 8 is the Last Chassis Switch. When closed (ON) the chassis is not the last chassis of a single ADAPTER number. When open (OFF) the chassis is the only chassis associated with a single ADAPTER number. The common EPICS setting for this switch is open (OFF).

\subsection{1-ASB Remote I/O Adapter Module Installation}

\subsubsection{Power Requirements}

The Allen-Bradley 1771-ASB Remote I/O Adapter Module may be installed in any AllenBradley Universal I/O Chassis, 1771-A1B, 1771-A2B, 1771-A3B, or 1771-A4B. Before Installation, calculate the power requirements of the modules currently in the chassis. Add to that 1.2A @ 5V DC, the current required by the 1771-ASB. Check to be sure that this combined current requirement does not exceed the current driving ability of the chassis power supply combination.

\subsubsection{Module Location in the $\mathrm{I} / \mathrm{O}$ Chassis}

The 171-ASB must be placed in the extreme left slot of the Universal I/O Chassis. It is suggested that this module be placed away from AC modules or high voltage DC modules to minimize electrical noise interference. 


\subsubsection{Module Keying}

The Allen Bradley Universal $\mathrm{I} / \mathrm{O}$ chassis have the ability to limit the slot access to certain modules by the implementation of a keying system. Modules are slotted in two places at the edge of the circuit board. The position of the keying bands on the backplane connector of the I/O chassis must correspond to these slots. To key a slot for use by the 1771-ASB Remote I/O Adapter only (this would in the case of the 1771-ASB be the left most slot), place the keying bands between 54 and 56 and between 16 and 18 on the I/O chassis backplane connector.

\subsubsection{Module Insertion}

Before a module is inserted into the Universal I/O Chassis, be sure that the power to the chassis is shut off. This can be done without shutting off the IOC that the Universal I/O Chassis is connected to. To insert the module, place it in the plastic tracks on the top and bottom of the Universal I/O Chassis. Slide the module into the Universal I/O Chassis until the module comes in contact with the backplane connector. Do not force the module in, instead apply firm and even pressure on the module to seat it properly on the backplane connector. Snap the chassis latch over the top of the module and connect the wiring arm to the module. The Universal I/O Chassis should begin communicating with the host IOC when power is reapplied, no rebooting of the IOC will have to be done.

\subsection{1-ASB Remote I/O Adapter Module Wiring Connection}

Connection of analog signals to the 1771-ASB are accomplished through the use of the wiring arm. Signals should be connected to the screw terminals on the wiring arm, as detailed in figure 4.4, and the wiring arm should be connected to the front tab connector on the $1771-\mathrm{ASB}$. If the $1771-\mathrm{ASB}$ is the last adapter on a link, or the only adapter on a link, be sure to add the I/O Channel terminator, Allen-Bradley Catalog \# 1770-XT to the wiring arm.

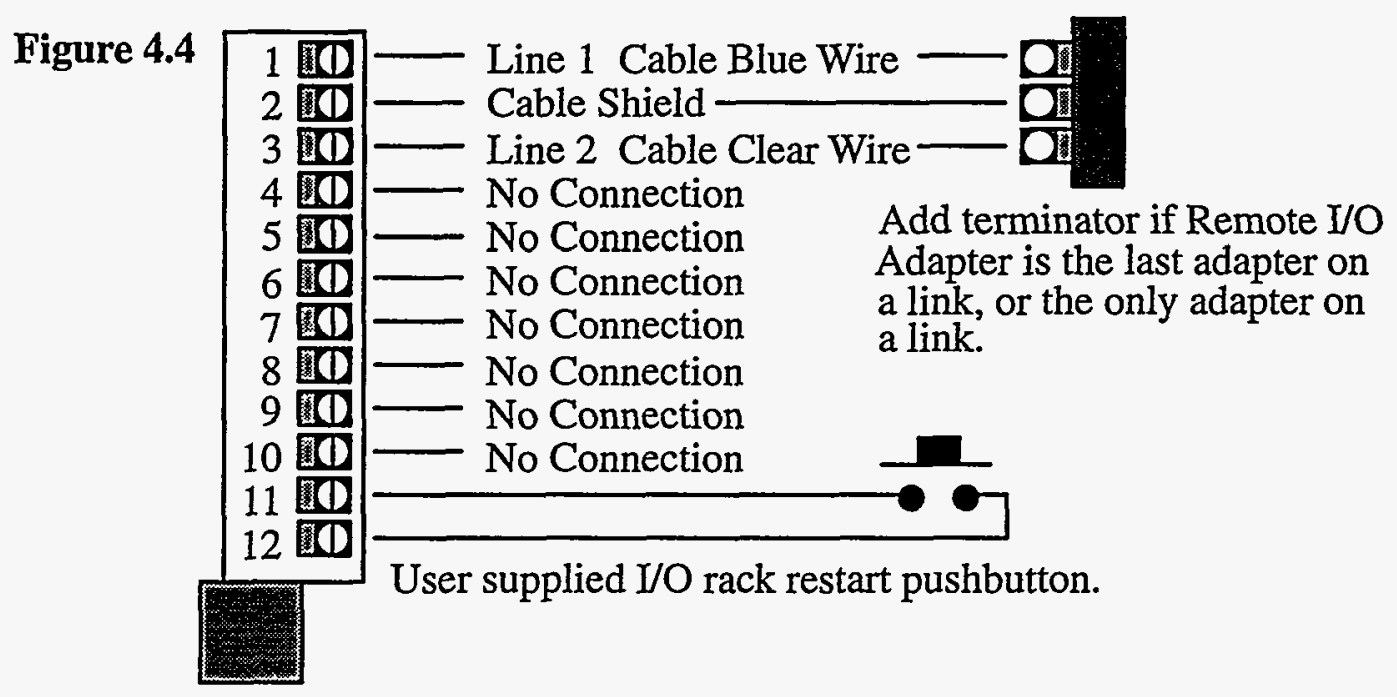




\subsection{1-ASB Remote I/O Adapter Module Use}

The front panel of the 1771-ASB contains a green ACTIVE, a red ADAPTER FAULT, and a red I/O RACK FAULT indicator. During normal operation the ACTIVE indicator should be illuminated, and the other two indicators should be out. The possible combinations of indicator actions are listed in figure 4.5.

Figure 4.5

\begin{tabular}{|c|c|c|l|}
\hline ACTIVE & $\begin{array}{c}\text { ADAPTER } \\
\text { FAULT }\end{array}$ & $\begin{array}{c}\text { I/O RACK } \\
\text { FAULT }\end{array}$ & \multicolumn{1}{|c|}{ INDICATION } \\
\hline On & Off & Off & Normal Operation \\
\hline Off & On & Off & Watchdog timeout - Module fault \\
\hline On & Blink & Off & Module placement error \\
\hline Blink in unison & Off & Incorrect starting I/O group number \\
\hline On & On & On & Module not communicating \\
\hline Off & On & On & Module not communicating \\
\hline Blink & Off & Off & Remote Adapter not controlling I/O \\
\hline Sequence on/off - top to bottom & Module not communicating \\
\hline Blink alternately & Off & Remote Adapter not controlling I/O \\
\hline Off & Off & On & I/O chassis fault - No communication link \\
\hline Blink & Off & On & Communication on link, possible shorted backplane \\
\hline Blink & On & Off & Module indentification line fault \\
\hline Off & Off & Off & Module not communicating \\
\hline
\end{tabular}




\section{CHAPTER 5 Allen-Bradley 1771-IFE Analog Input Module}

\subsection{1-IFE Analog Input Module}

The 1771-IFE senses up to 16 single-ended or 8 differential analog inputs and converts them to a proportional 12 bit binary value. Its use with the EPICS control system supports 3 voltage ranges and 1 current range, selectable on a per channel basis. Supported input ranges include:

Voltages

Currents

0 to $5 \mathrm{~V} \mathrm{DC}$ (differential)

4 to $20 \mathrm{~mA}$ (differential)

-10 to $10 \mathrm{~V} \mathrm{DC}$ (single ended)

-10 to $10 \mathrm{~V} \mathrm{DC}$ (differential)

\subsection{1-IFE Analog Input Module Strapping}

Remove the module's left hand cover plate (the one without the labels). Observe the location of the configuration jumpers in figure 5.1, and note the location of the individual channels.

Figure 5.1

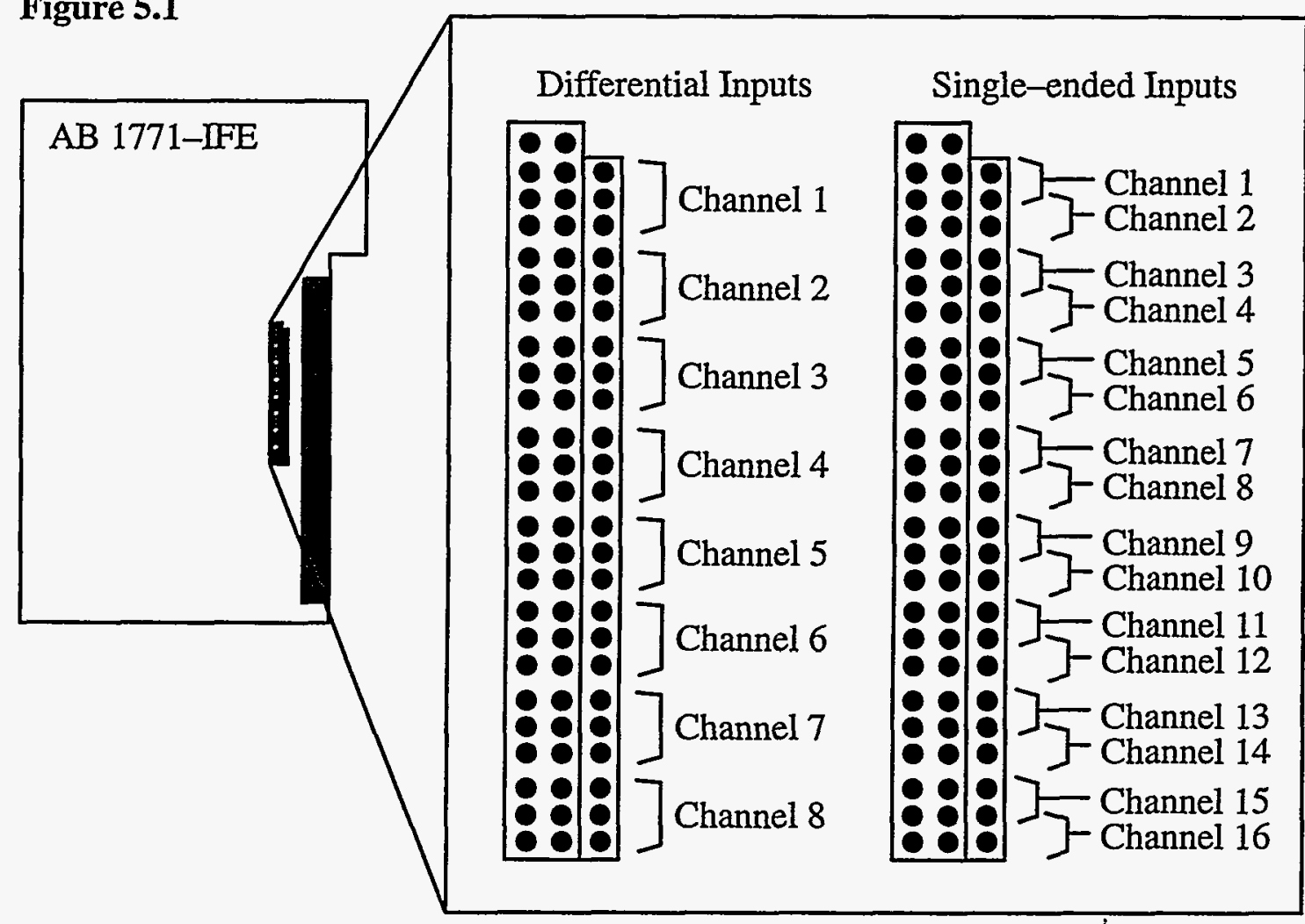

The input range is determined in software, however the single-ended or differential determination, as well as the type of input, voltage or current, is configured by the above jumpers. Figure 5.2 contains diagrams detailing this information. Refer to figure 5.1 for channel clarification. 
Figure 5.2

Single-ended Inputs

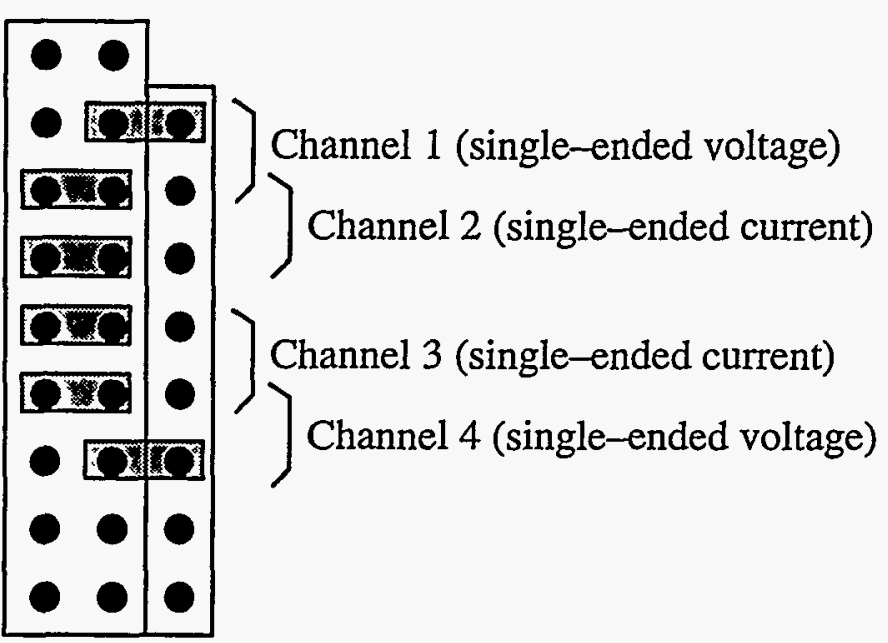

Differential Inputs

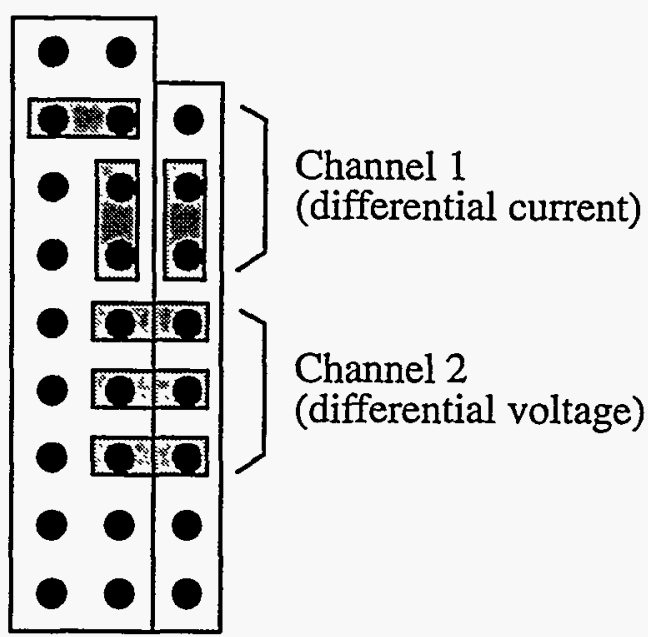

Note that this illustration details only the top few jumper points

\subsection{1-IFE Analog Input Module Installation}

\subsubsection{Power Requirements}

The Allen-Bradley 1771-IFE Analog Input Module may be installed in any Allen-Bradley Universal I/O Chassis, 1771-A1B, 1771-A2B, 1771-A3B, or 1771-A4B. Before Installation, calculate the power requirements of the modules currently in the chassis. Add to that $750 \mathrm{~mA} @ 5 V D C$, the current required by the 1771-IFE. Check to be sure that this combined current requirement does not exceed the current driving ability of the chassis power supply.

\subsubsection{Module Location in the I/O Chassis}

The 1771-IFE may be placed in any slot of the I/O chassis with the exception of of the extreme left slot. This slot is occupied by the Remote I/O Adapter Module. It is suggested that analog input modules and low voltage $\mathrm{DC}$ modules be placed away from $\mathrm{AC}$ modules or high voltage DC modules to minimize electrical noise interference.

\subsubsection{Module Keying}

The Allen Bradley Universal I/O chassis have the ability to limit the slot access to certain modules by the implementation of a keying system. Modules are slotted in two places at the edge of the circuit board. The position of the keying bands on the backplane connector of the I/O chassis must correspond to these slots. To key a slot for use by the 1771-IFE Analog Input only, place the keying bands between 10 and 12 and between 24 and 26 on the I/O chassis backplane connector.

\subsubsection{Module Insertion}

Before a module is inserted into the Universal I/O Chassis, be sure that the power to the chassis is shut off. This can be done without shutting off the IOC that the Universal I/O Chassis is connected to, and without removing the subnet communication link. To insert the module, place it in the plastic tracks on the top and bottom of the Universal I/O Chassis. Slide the 
module into the Universal I/O Chassis until the module comes in contact with the backplane connector. Do not force the module in, instead apply firm and even pressure on the module to seat it properly on the backplane connector. Snap the chassis latch over the top of the module and connect the wiring arm to the module. The Universal I/O Chassis should begin communicating with the host IOC when power is reapplied, no rebooting of the IOC will have to be done.

\subsection{1-IFE Analog Input Module Wiring Connection}

Connection of analog signals to the 1771-IFE is accomplished through the use of the wiring arm. Signals should be connected to the screw terminals on the wiring arm, as detailed in figure 5.3, and the wiring arm should be connected to the front tab connector on the 1771-IFE. The recommend cable length for voltage signals is $50 \mathrm{ft}$. This is based on considerations of signal degradation and electrical noise immunity in typical industrial environments. When shielded cable is used and grounding of the shield is desired, it is recommended that the connection be made at one of the I/O chassis mounting bolts. To prevent ground loops only one end of the cable shield should be grounded.

\section{Figure 5.3}

Single-ended Inputs

\begin{tabular}{|c|c|}
\hline 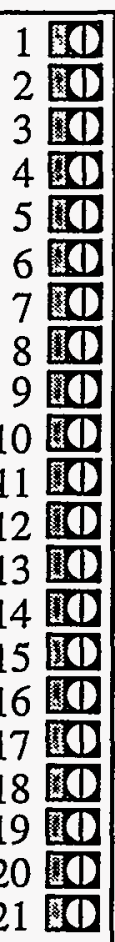 & $\begin{array}{l}\text { Channel } 1 \\
\text { Channel } 2 \\
\text { Channel } 3 \\
\text { Channel } 4 \\
\text { Module Common } \\
\text { Channel } 5 \\
\text { Channel } 6 \\
\text { Channel } 7 \\
\text { Channel } 8 \\
\text { Module Common } \\
\text { Channel } 9 \\
\text { Channel } 10 \\
\text { Channel } 11 \\
\text { Channel } 12 \\
\text { Module Common } \\
\text { Channel } 13 \\
\text { Channel } 14 \\
\text { Channel } 15 \\
\text { Channel } 16 \\
\text { Module Common } \\
\text { Module Common }\end{array}$ \\
\hline
\end{tabular}

Differential Inputs

\begin{tabular}{|c|c|}
\hline 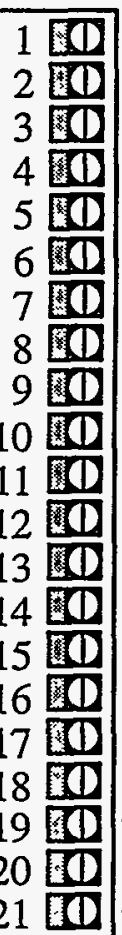 & 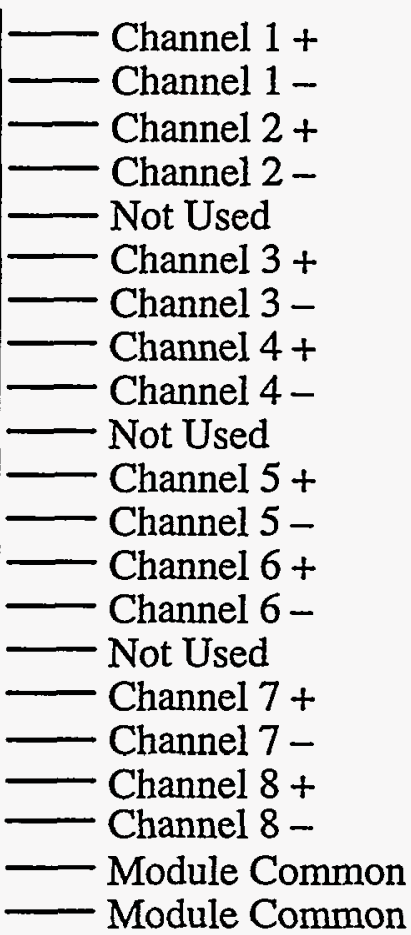 \\
\hline
\end{tabular}

\subsection{1-IFE Analog Input Module Use :}

The front panel of the 1771-IFE contains a green RUN and a red FAULT indicator. At power up an initial module self-check occurs. If there is no fault the red indicator will turn off. The green indicator will flash until the processor communicates successfully with the module. 


\section{CHAPTER 6 Allen-Bradley 1771-OFE Analog Output Module}

\subsection{1-OFE Analog Output Module}

The 1771-OFE is an intelligent block transfer module that converts binary or four digit BCD values to analog signals. The 1771-OFE controls four differential voltage or current outputs. The module is available in two versions, the 1771-OFE1 for voltage outputs, and the 1771-OFE2 for current outputs. Its use with the EPICS control system supports 1 current range, and 3 voltage ranges, the voltage ranges are selectable on a per channel basis. Supported input ranges include:

\begin{tabular}{ll}
$\begin{array}{l}\text { Voltages } \\
1771-O F E 1\end{array}$ & $\begin{array}{l}\text { Currents } \\
1771-O F E 2\end{array}$ \\
\hline 1 to 5 V DC & 4 to $20 \mathrm{~mA}$ \\
0 to $10 \mathrm{~V} \mathrm{DC}$ & \\
-10 to $10 \mathrm{~V} \mathrm{DC}$ &
\end{tabular}

The output specifications for the voltage ranges dictate a maximum of $10 \mathrm{~mA}$ per channel. The output specifications for the current ranges dictate a maximum of $1200 \mathrm{ohms}$ per channel of load resistance.

\subsection{1-OFE Analog Output Module Strapping}

Both the 1771-OFE1 (voltage output module) and the 1771-OFE2 (current output module) have a configuration strap for the test mode output level. Only the 1771-OFE1 (voltage output module) requires the configuration of module straps for the individual channel ranges, the 1771-OFE2 (current output module) has no such jumpers. Remove the module's right hand cover plate (the one with the labels) by removing the four screws on that side. This will expose the bottom side of the printed circuit board and three more screws which must be removed for complete circuit board removal. Observe the location of the configuration jumpers in figure 6.1, and note the location of the individual channels.

The Test Mode Output jumper (1771-OFE1 and 1771-OFE2) controls the magnitude of the outputs if the module should receive a reset condition from the control system. For instance, if a module output is set for a 0 to $10 \mathrm{~V} \mathrm{DC}$ range, and the Test Mode Output is set to $\mathrm{MID}$, if the module resets, the output will will be forced to $5 \mathrm{~V} \mathrm{DC}$. If no jumpers are placed on the Test Mode Output configuration plug, the module will default to MID. Note that if Switch 1 of the DIP switch assembly on the Universal I/O chassis is set closed (ON), the module's outputs will remain in their last state ignoring the Test Mode Output Jumper.

The Range selection jumpers (1771-OFE1 only) are set individually for each channel according to the range desired as illustrated in figure 6.1.

\subsection{1-OFE Analog Output Module Installation}

\subsubsection{Power Requirements}

The Allen-Bradley 1771-OFE Analog Output Module may be installed in any Allen-Bradley Universal I/O Chassis, 1771-A1B, 1771-A2B, 1771-A3B, or 1771-A4B. Before Installation, calculate the power requirements of the modules currently in the chassis. Add to that 1.5A @ 5V DC, the current required by the 1771-OFE. Check to be sure that this 
Figure 6.1

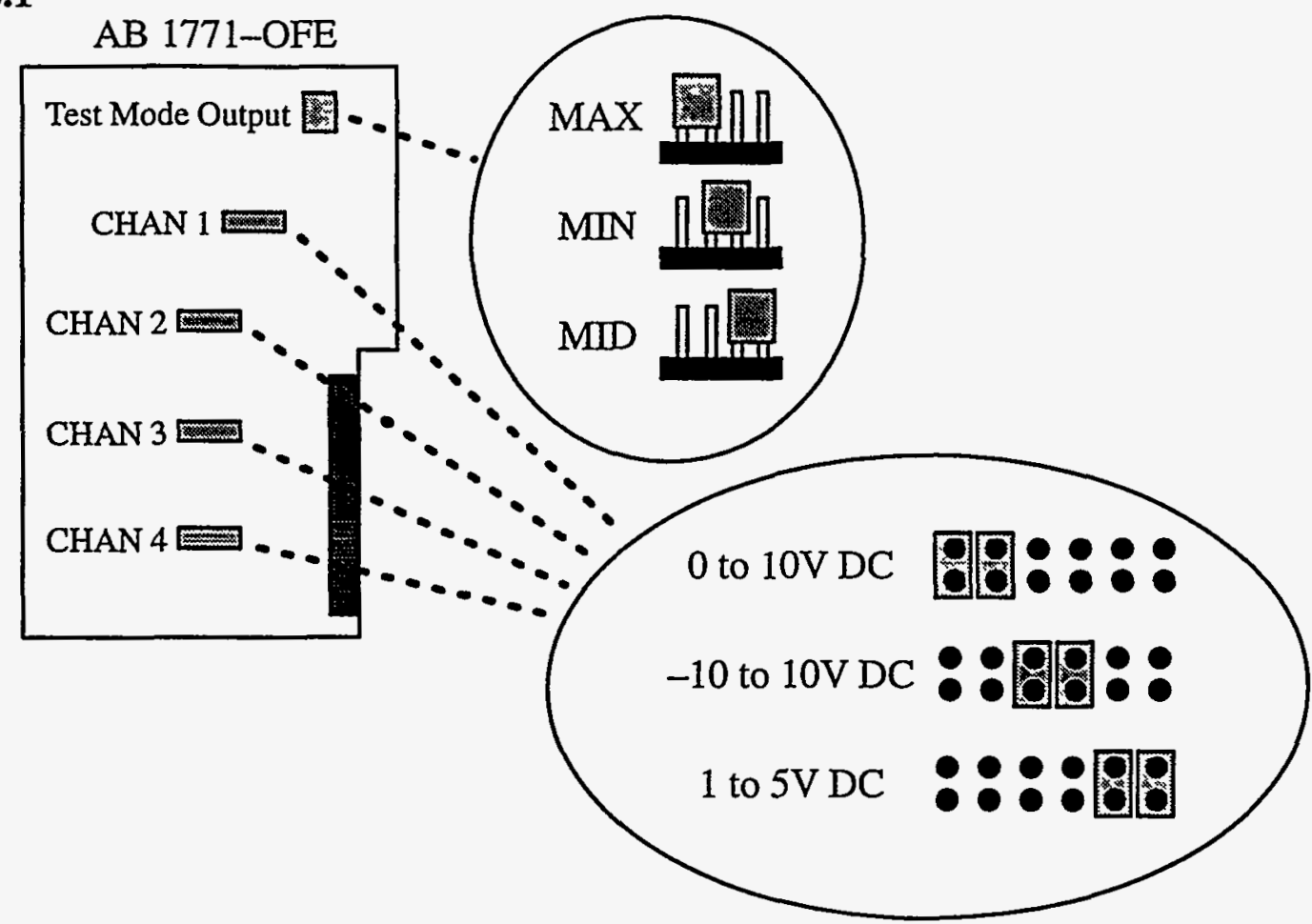

combined current requirement does not exceed the current driving ability of the chassis power supply.

\subsubsection{Module Location in the I/O Chassis}

The 1771-OFE may be placed in any slot of the I/O chassis with the exception of of the extreme left slot. This slot is occupied by the Remote I/O Adapter Module. It is suggested that analog input modules and low voltage $\mathrm{DC}$ modules be placed away from $\mathrm{AC}$ modules or high voltage DC modules to minimize electrical noise interference.

\subsubsection{Module Keying}

The Allen Bradley Universal I/O chassis have the ability to limit the slot access to certain modules by the implementation of a keying system. Modules are slotted in two places at the edge of the circuit board. The position of the keying bands on the backplane connector of the I/O chassis must correspond to these slots. To key a slot for use by the 1771-OFE Analog Out put only, place the keying bands between 10 and 12 and between 26 and 28 on the I/O chassis backplane connector.

\subsubsection{Module Insertion}

Before a module is inserted into the Universal I/O Chassis, be sure that the power to the chassis is shut off. This can be done without shutting off the IOC that the Universal I/O Chassis is connected to, and without removing the subnet communication link. To insert the module, place it in the plastic tracks on the top and bottom of the Universal I/O Chassis. Slide the module into the Universal I/O Chassis until the module comes in contact with the backplane connector. Do not force the module in, instead apply firm and even pressure on the module 
to seat it properly on the backplane connector. Snap the chassis latch over the top of the module and connect the wiring arm to the module. The Universal I/O Chassis should begin communicating with the host IOC when power is reapplied, no rebooting of the IOC will have to be done.

\subsection{1-OFE Analog Output Module Wiring Connection}

Connection to the analog signals of the 1771-OFE is accomplished through the use of the wiring arm. Signals should be connected to the screw terminals on the wiring arm, as detailed in figure 6.2 , and the wiring arm should be connected to the front tab connector on the 1771-OFE. The recommend cable length for voltage signals is $50 \mathrm{ft}$. This is based on considerations of signal degradation and electrical noise immunity in typical industrial environments. When shielded cable is used and grounding of the shield is desired, it is recommended that the connection be made at one of the I/O chassis mounting bolts. To prevent ground loops only the chassis end of the cable shield should be grounded.

Figure 6.2

1771-OFE Differential Outputs

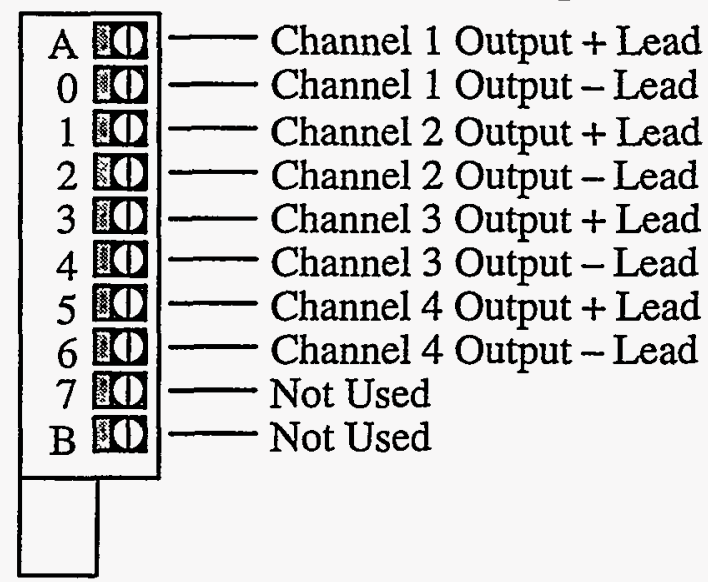

\subsection{1-OFE Analog Output Module Use}

The front panel of the 1771-OFE contains a green RUN and a red FAULT indicator. At power up the green indicator will light and remain on. At power up an initial module self-check occurs. If a fault is found initially or occurs later, the red indicator will turn on. 


\section{CHAPTER 7 Allen-Bradley 1771-IG(D) TTL Input Module}

\subsection{1-IG(D) TTL Input Module}

Allen-Bradley has two versions of the TTL compatible discrete Input modules that will interface to TTL output devices. The $1771-\mathrm{IG}$ module will monitor eight TTL inputs while the 1771-IGD will monitor up to 16 inputs. Only the $1771-\mathrm{IG}$ version has a $1 \mathrm{~ms}$ input filter, while the 1771-IGD version has input diode protection to +5 volts and ground. The TTL voltage ranges are $0-0.5 \mathrm{~V} D C$ for $\mathrm{V}$ low, and $2.7-5.25 \mathrm{~V} \mathrm{DC}$ for $\mathrm{V}$ high. The modules are current rated at I in low, $7 \mathrm{~mA}$ source current (the device connected to the module must be able to sink this current and any current from pull up resistors), and I in high, $0.8 \mathrm{~mA}$ (the module will sink this much current).

\subsection{1-IG(D) TTL Input Module Strapping}

\subsubsection{1-IG TTL Input Module Strapping}

Remove the module's left hand cover plate (the one without the labels). Observe the location of the configuration switches in figure 7.1. When selecting POSITIVE logic, switch 1 and

Figure 7.1

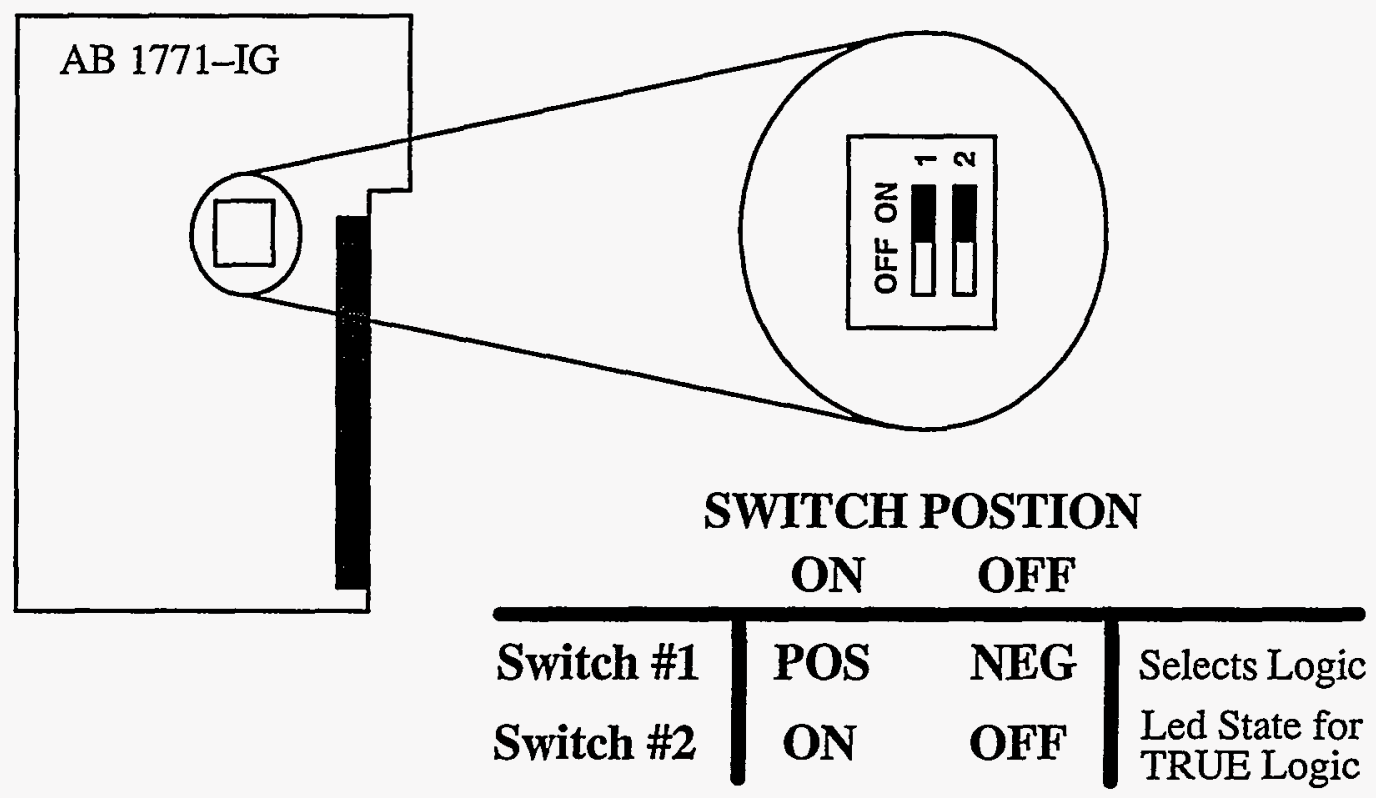

2 are generally set to the ON position. For NEGATIVE logic, switch 1 and 2 are generally set to the OFF position.

\subsubsection{1-IGD TTL Input Module Strapping}

Remove the module's left hand cover plate (the one without the labels). Observe the location of the jumper figure 7.2. When selecting POSITIVE logic, set the jumper to the HIGH (left/ rear) position. For NEGATIVE logic, set the jumper to the LOW (right/front) position. 
Figure 7.2

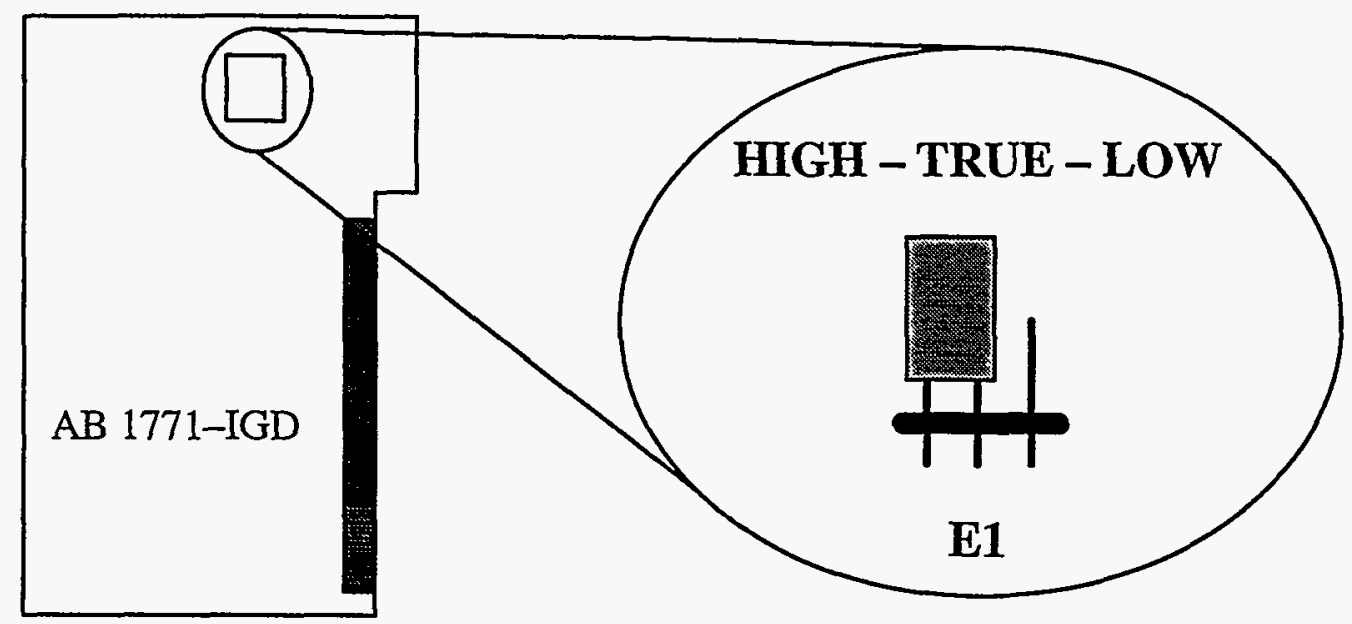

\subsection{1-IG(D) TTL Input Module Installation}

\subsubsection{Power Requirements}

The Allen-Bradley 1771-IG(D) TTL Input Module may be installed in any Allen-Bradley Universal I/O Chassis, 1771-A1B, 1771-A2B, 1771-A3B, or 1771-A4B. Before Installation, calculate the power requirements of the modules currently in the chassis. Add to that 122mA @ 5V DC for the 1771-IG, or 50mA @ 5V DC for the 1771-IGD. Check to be sure that this combined current requirement does not exceed the current driving ability of the chassis power supply.

Only the 1771-IGD module has a fuse to protect the +5V DC power supply and the module's input terminals from the accidental application of voltage that could cause damage: voltage over 6.0V DC, reverse DC or AC voltage. Fuse rating: $0.5 \mathrm{~A}$ at $250 \mathrm{~V}$, use Littelfuse 312.250 or similar.

The 1771-IG is not fuse protected so care must be taken to properly connect the power supply. Accidental application of AC, reverse DC, or over voltage could damage the module.

\subsubsection{Module Location in the I/O Chassis}

The 1771-IG(D) may be placed in any slot of the I/O chassis with the exception of of the extreme left slot. This slot is occupied by the Remote I/O Adapter Module. It is suggested that analog input modules and low voltage DC modules be placed away from AC modules or high voltage DC modules to minimize electrical noise interference.

The 1771-IGD has an additional restriction. EPICS software reads and writes the AllenBradly chassis in Two-slot addressing mode. A module group is considered to contain two Allen-Bradly slots. The first module group address is located at slot 0 and 1 . The second is slot 2 and 3 and so on. When using a 16-bit input module in a two-slot addressing mode, the input module must always be inserted into an even number slot (left-hand side of the module group). A complementary output module (8-bit or 16-bit module) may be inserted into an odd number slot (right-hand side of the module group) completing the module group. If no complementary module is used then that slot must remain empty. 
The 1771-IG has no such restriction. An 8-bit input module can be used with any 8-bit input or output module. There is no defined order as to which input or output module is inserted in a module group, and two inputs or two outputs can be used in the same module group. However, it is common practice when using an 8-bit input and an 8-bit output module in a module group, to insert the input module into the even (left-hand) slot and the the output module into the odd (right hand) slot of the module group.

\subsubsection{Module Keying}

The Allen Bradley Universal I/O chassis have the ability to limit the slot access to certain modules by the implementation of a keying system. Modules are slotted in two places at the edge of the circuit board. The position of the keying bands on the backplane connector of the I/O chassis must correspond to these slots. To key a slot for use by the 1771-IG TTL Input only, place the keying bands between 4 and 6 and between 34 and 36 on the I/O chassis backplane connector. To key a slot for use by the 1771-IGD TTL Input only, place the keying bands between 16 and 18 and between 24 and 26 on the I/O chassis backplane connector.

\subsubsection{Module Insertion}

Before a module is inserted into the Universal I/O Chassis, be sure that the power to the chassis is shut off. This can be done without shutting off the IOC that the Universal I/O Chassis is connected to, and without removing the subnet communication link. To insert the module, place it in the plastic tracks on the top and bottom of the Universal I/O Chassis. Slide the module into the Universal I/O Chassis until the module comes in contact with the backplane connector. Do not force the module in, instead apply firm and even pressure on the module to seat it properly on the backplane connector. Snap the chassis latch over the top of the module and connect the wiring arm to the module. The Universal I/O Chassis should begin communicating with the host IOC when power is reapplied, no rebooting of the IOC will have to be done.

\subsection{1-IG(D) TTL Input Module Wiring Connection}

Connecting field wiring to the 1771-IG(D) is accomplished through the use of a shielded cable to the wiring arm. Signals should be connected to the screw terminals on the wiring arm, as detailed in figure 7.3, and the wiring arm should be connected to the front tab connector on the 1771-IG(D). When shielded cable is used and grounding of the shield is desired, it is recommended that the connection be made at one of the I/O chassis mounting bolts. To prevent ground loops only the chassis end of the cable shield should be grounded.

\subsection{1-IG(D) TTL Input Module Use}

The front panel on the 1771-IG contains nine red LED indicators. The top red LED labeled HIGH-TRUE indicates the module is selected for positive logic when illuminating. The next eight LEDs will indicate if an individual input is true.

The front panel on the 1771-IGD contains 18 LED indicators. The top green LED labeled ACTIVE indicates the module is connected to +5 volts and the fuse on the 1771-IGD is not blown. The next 16 red LED indicators, labeled 00 through 17 (octal), will indicate if an input is true. The last green LED labeled HIGH indicates the module is selected for positive logic when illuminating. 
Figure 7.3

1771-IG Input Connections

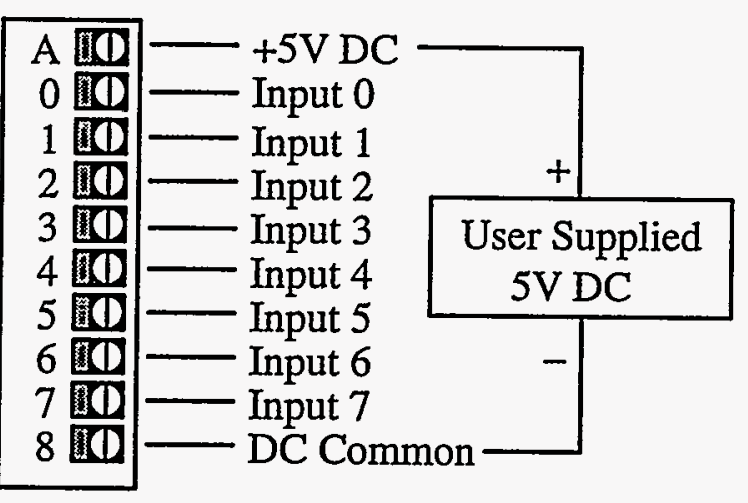

1771-IGD Input Connections

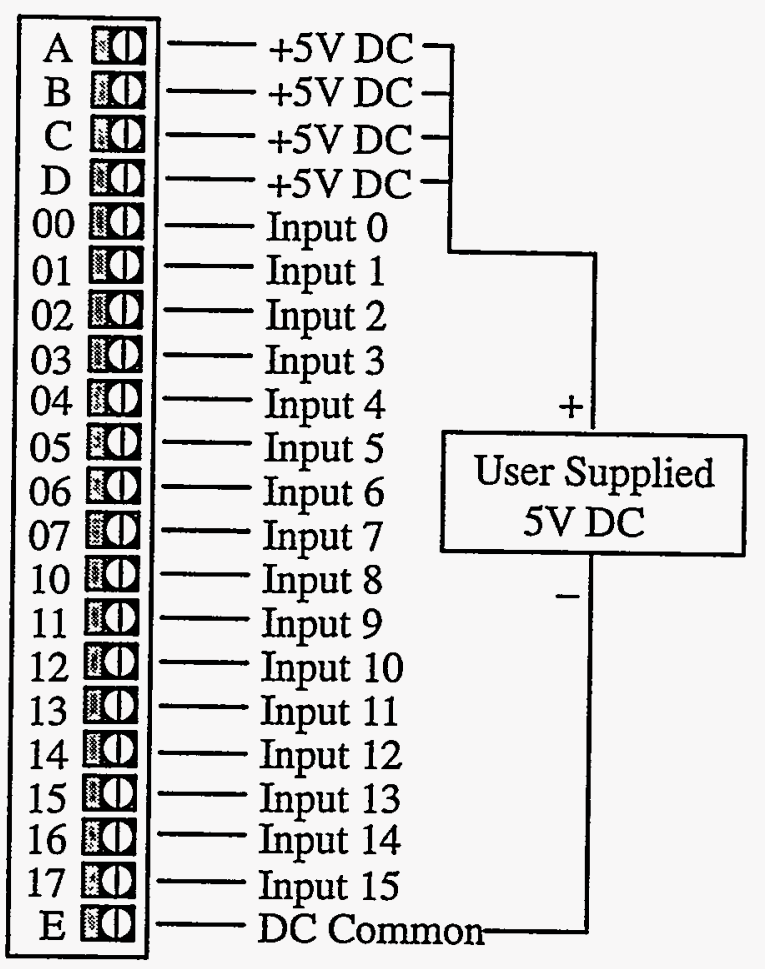




\section{CHAPTER 8 Allen-Bradley 1771-OG(D) TTL Output}

\subsection{1-OG(D) TTL Output Module}

Allen-Bradley has two versions of the TTL compatible discrete Output modules that will interface to TTL output devices. The 1771-OG module will control eight TTL outputs while the 1771-OGD will control up to 16 outputs. Only the $1771-O G$ version has a $1 \mathrm{~ms}$ output filter, while the $1771-O G D$ version has output diode protection to +5 volts and ground. The TTL voltage ranges are $0-0.5 \mathrm{~V} \mathrm{DC}$ for $\mathrm{V}$ low, and $2.7-5.25 \mathrm{~V} \mathrm{DC}$ for $\mathrm{V}$ high. The modules are current rated at I out low, $20 \mathrm{~mA}$ sink current (the device connected to the module must source no more than this amount), and I out high, $1 \mathrm{~mA}$ (the module will source this much current).

\subsection{1-OG(D) TTL Output Module Strapping}

\subsubsection{1-OG TTL Output Module Strapping}

Remove the module's left hand cover plate (the one without the labels). Observe the location of the configuration switches in figure 7.1. When selecting POSITIVE logic, switch 1 and

Figure 7.1

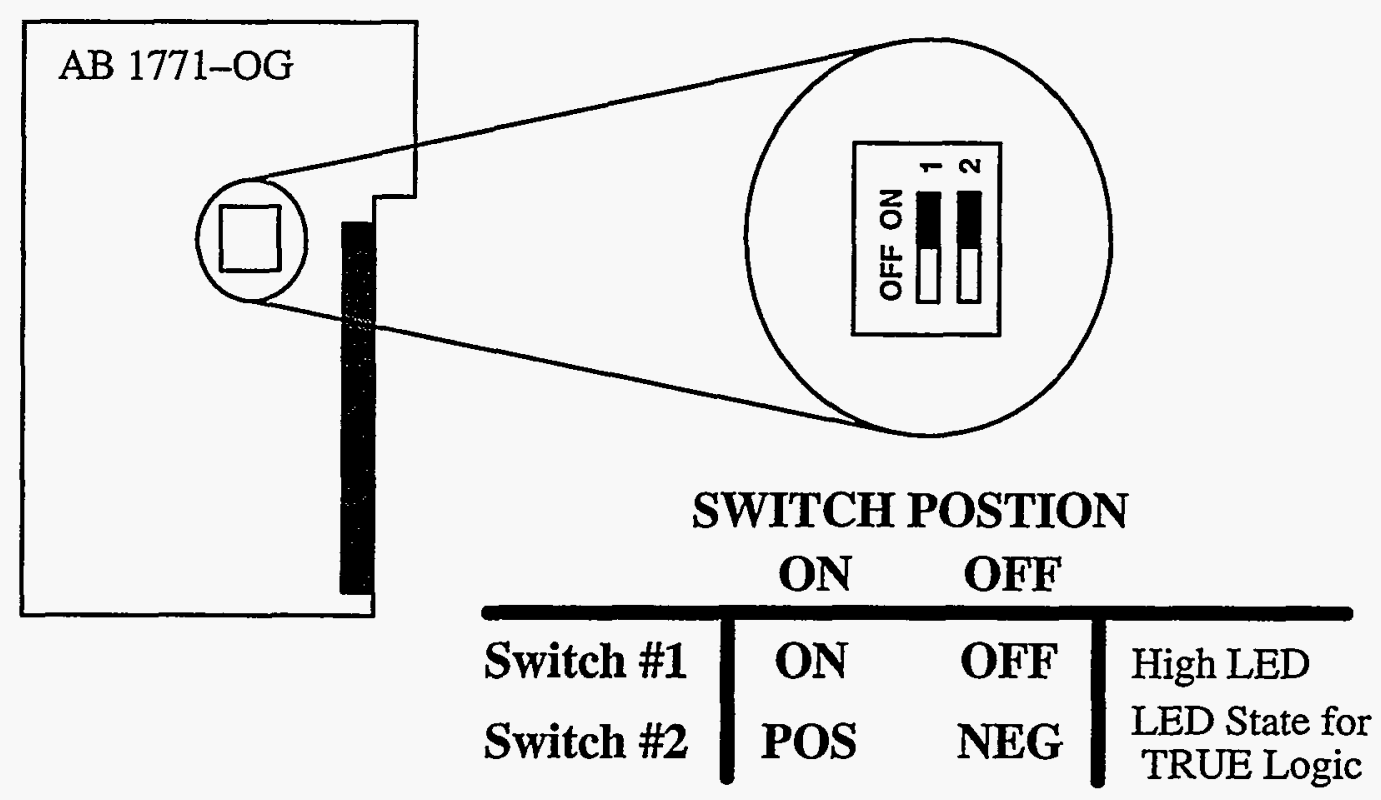

2 are set to the ON position. For NEGATIVE logic, switch 1 and 2 are generally set to the OFF position.

\subsubsection{1-OGD TTL Output Module Strapping}

Remove the module's left hand cover plate (the one without the labels). Observe the location of the configuration switches figure 7.2 When selecting POSITIVE logic, set strap to the HIGH (right/front) position. For NEGATIVE logic, set strap to the LOW (left/rear) position. 
Figure 7.2

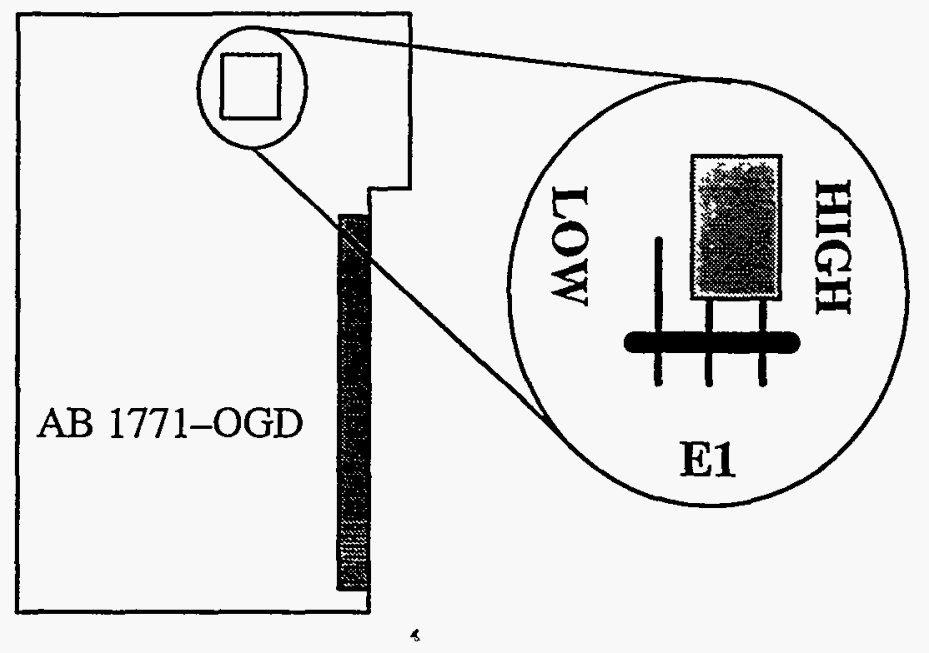

\subsection{1-OG(D) TTL Output Module Installation}

\subsubsection{Power Requirements}

The Allen-Bradley 1771-OG(D) TTL Output Module may be installed in any Allen-Bradley Universal I/O Chassis, 1771-A1B, 1771-A2B, 1771-A3B, or 1771-A4B. Before Installation, calculate the power requirements of the modules currently in the chassis. Add to that 168mA @ 5V DC for the 1771-OG, or 230mA @ 5V DC for the 1771-OGD. Check to be sure that this combined current requirement does not exceed the current driving ability of the chassis power supply.

Only the 1771-OGD module has a fuse to protect the $+5 \mathrm{~V}$ DC power supply and the module's output terminals from the accidental application of voltage that could cause damage, such as voltage over $6.0 \mathrm{~V} \mathrm{DC}$, reverse $\mathrm{DC}$ or AC voltage. Fuse rating: $0.5 \mathrm{~A}$ at $250 \mathrm{~V}$, use Littelfuse 312.250 or similar.

The 1771-OG is not fuse protected so care must be taken to properly connect the power supply. Accidental application of AC, reverse DC, or over voltage could damage the module.

\subsubsection{Module Location in the $\mathrm{I} / \mathrm{O}$ Chassis}

The 1771-OG(D) may be placed in any slot of the $I / O$ chassis with the exception of of the extreme left slot. This slot is occupied by the Remote I/O Adapter Module. It is suggested that analog input modules and low voltage $\mathrm{DC}$ modules be placed away from $\mathrm{AC}$ modules or high voltage $\mathrm{DC}$ modules to minimize electrical noise interference.

The 1771-OGD has an additional restriction. EPICS software reads and writes the AllenBradly chassis in Two-slot addressing mode. A module group is considered to contain two Allen-Bradly slots. The first module group address is located at slot 0 and 1 . The second is slot 2 and 3 and so on. When using a 16-bit output module in a two-slot addressing mode, the output module must always be inserted into an odd number slot (right-hand side of the module group). A complementary input module (8-bit or 16-bit module) may be inserted into an even number (left-hand side of the module group) slot completing the module group. If no complementary module is used then that slot must remain empty. 
The 1771-IG has no such restriction. An 8-bit output module can be used with any 8-bit input or output module. There is no defined order as to which input or output module is inserted in a module group, and two inputs or two outputs can be used in the same module group. However, it is common practice when using an 8-bit output and an 8-bit input module in a module group, to insert the output module into the odd (right-hand) slot and the the input module into the even (left-hand) slot of the module group.

\subsubsection{Module Keying}

The Allen Bradley Universal I/O chassis have the ability to limit the slot access to certain modules by the implementation of a keying system. Modules are slotted in two places at the edge of the circuit board. The position of the keying bands on the backplane connector of the I/O chassis must correspond to these slots. To key a slot for use by the 1771-OG TTL Output only, place the keying bands between 6 and 8 and between 10 and 12 on the I/O chassis backplane connector. To key a slot for use by the 1771-OGD TTL Output only, place the keying bands between 16 and 18 and between 26 and 28 on the I/O chassis backplane connector.

\subsubsection{Module Insertion}

Before a module is inserted into the Universal I/O Chassis, be sure that the power to the chassis is shut off. This can be done without shutting off the IOC that the Universal I/O Chassis is connected to, and without removing the subnet communication link. To insert the module, place it in the plastic tracks on the top and bottom of the Universal I/O Chassis. Slide the module into the Universal I/O Chassis until the module comes in contact with the backplane connector. Do not force the module in, instead apply firm and even pressure on the module to seat it properly on the backplane connector. Snap the chassis latch over the top of the module and connect the wiring arm to the module. The Universal I/O Chassis should begin communicating with the host IOC when power is reapplied, no rebooting of the IOC will have to be done.

\subsection{1-OG(D) TTL Output Module Wiring Connection}

Connecting field wiring to the 1771-OG(D) is accomplished through the use of a shielded cable to the wiring arm. Signals should be connected to the screw terminals on the wiring arm, as detailed in figure 8.3, and the wiring arm should be connected to the front tab connector on the 1771-OG(D). When shielded cable is used and grounding of the shield is desired, it is recommended that the connection be made at one of the I/O chassis mounting bolts. To prevent ground loops only the chassis end of the cable shield should be grounded.

\subsection{1-OG(D) TTL Output Module Use}

The front panel on the 1771-OG contains nine red LED indicators. The top red LED labeled HIGH-TRUE indicates the module is selected for positive logic when illuminating. The next eight LEDs will indicate if an output is true.

The front panel on the 1771-OGD contains 18 LED indicators. The top green LED labeled ACTIVE indicates the module is connected to +5 volts and the fuse on the 1771-OGD is not blown. The next 16 red LED indicators, labeled 00 through 17 (octal), will indicate if an output is true. The last green LED labeled HIGH indicates the module is selected for positive logic when illuminating. 
Figure 8.3

1771-OG Output Connections

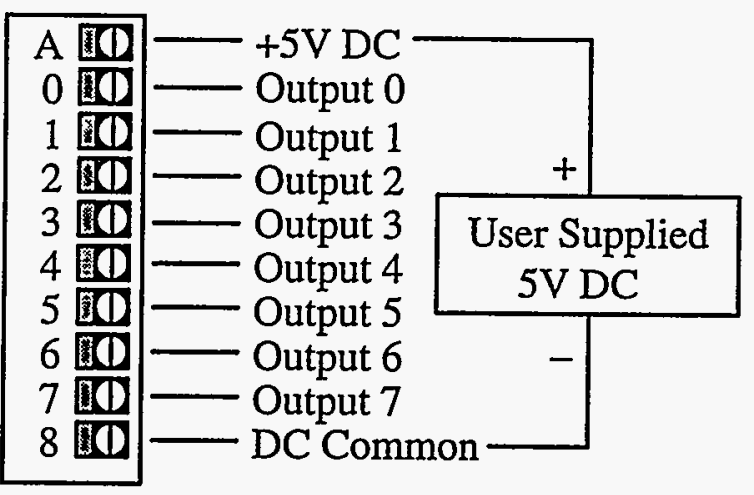

1771-OGD Output Connections

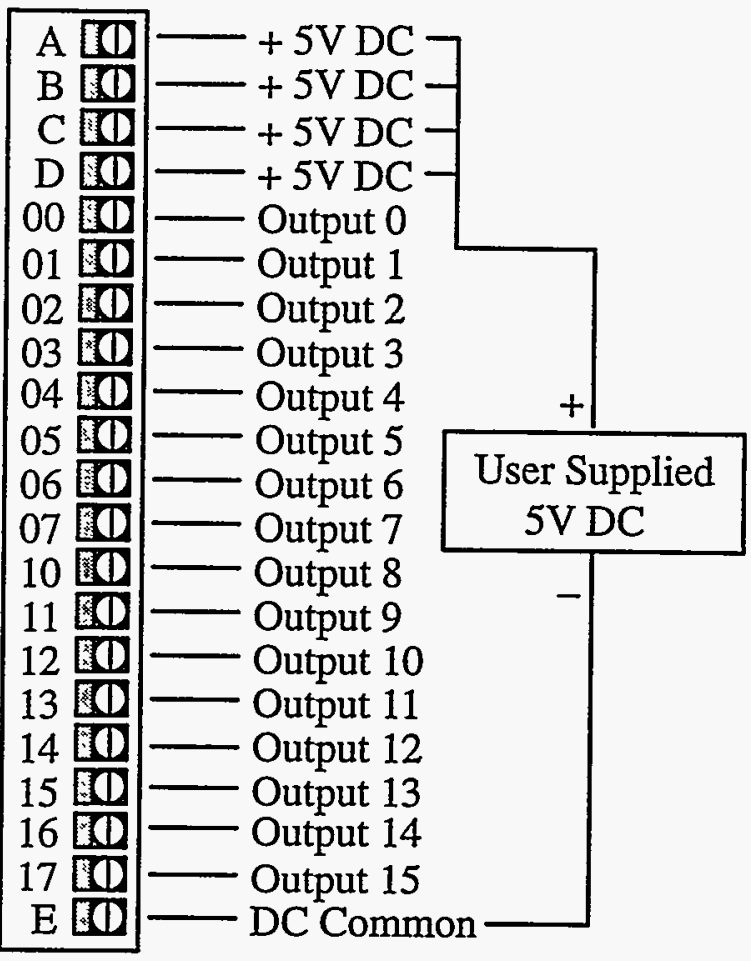




\section{CHAPTER 9 Allen-Bradley 1771-IQ DC Selectable Input Module}

\subsection{1-IQ DC Selectable Input Module}

The 1771-IQ DC (5-30V) Input module accepts DC voltage levels on all 8 inputs and converts these signals to logic levels. Each input circuit is individually selectable for current source (current flowing from the 1771-IQ to the DC input device) or current sink capability (current flowing from the DC input device to the 1771-IQ). This module may also be configured from either HIGH TRUE or LOW TRUE logic with an input delay of $1 \mathrm{~ms}$ maximum or $12 \mathrm{~ms}$ typical. For the HIGH TRUE setting TRUE is any voltage greater than $40 \%$ of the external supply voltage, and LOW is any voltage less than $20 \%$ of the external supply voltage. For the LOW TRUE setting, HIGH is any voltage less than $20 \%$ of the external supply voltage, and LOW is any voltage greater than $40 \%$ of the external supply voltage. The nominal input current per channel for an ON condition is $5 \mathrm{~mA}$ for $5 \mathrm{~V} \mathrm{DC}$, and $25 \mathrm{~mA}$ for $30 \mathrm{VDC}$. The external supply voltage power supply must be able to provide $100 \mathrm{~mA}$ per module at $5 \mathrm{~V}$ $\mathrm{DC}$, and $350 \mathrm{~mA}$ per module at $30 \mathrm{~V}$ DC.

\subsection{1-IQ DC Selectable Input Module Strapping}

Remove the module's left hand cover plate (the one without the labels). Observe the location of the configuration switches below, and note the location of the individual channels as illustrated in figure 9.1. Switch bank SW-1 is used to configure the input delay, and the true level of the logic. Figure 9.1 contains sufficient information to describe these switch settings. Switch bank SW-2 and SW-3 are used to configure each input individually for either current sink or current source. For current sink set SW-2 to the ON position and SW-3 to the OFF position for the appropriate input signal (switch 1 corresponds to signal 0 , and switch 8 corresponds to signal 7). For current source set SW-2 to the OFF position and SW-3 to the ON position for the appropriate input signal (switch 1 corresponds to signal 0 , and switch 8 corresponds to signal 7). Note: setting an individual channel's SW-2 and SW-3 switch to either both on. or both off is an invalid setting.

\subsection{1-IQ DC Selectable Input Module Installation}

\subsubsection{Power Requirements}

The Allen-Bradley 1771-IQ Contact Output Module may be installed in any Allen-Bradley Universal I/O Chassis, 1771-A1B, 1771-A2B, 1771-A3B, or 1771-A4B. Before Installation, calculate the power requirements of the modules currently in the chassis. Add to that $150 \mathrm{~mA} @ 5 \mathrm{~V} \mathrm{DC}$, the current required by the 1771-IQ. Check to be sure that this combined current requirement does not exceed the current driving ability of the chassis power supply.

\subsubsection{Module Location in the I/O Chassis}

The 1771-IQ may be place in any slot of the I/O chassis with the exception of of the extreme left slot. This slot is occupied by the Remote I/O Adapter Module. It is suggested that analog input modules and low voltage $\mathrm{DC}$ modules be placed away from $\mathrm{AC}$ modules or high voltage $\mathrm{DC}$ modules to minimize electrical noise interference. 
Figure 9.1

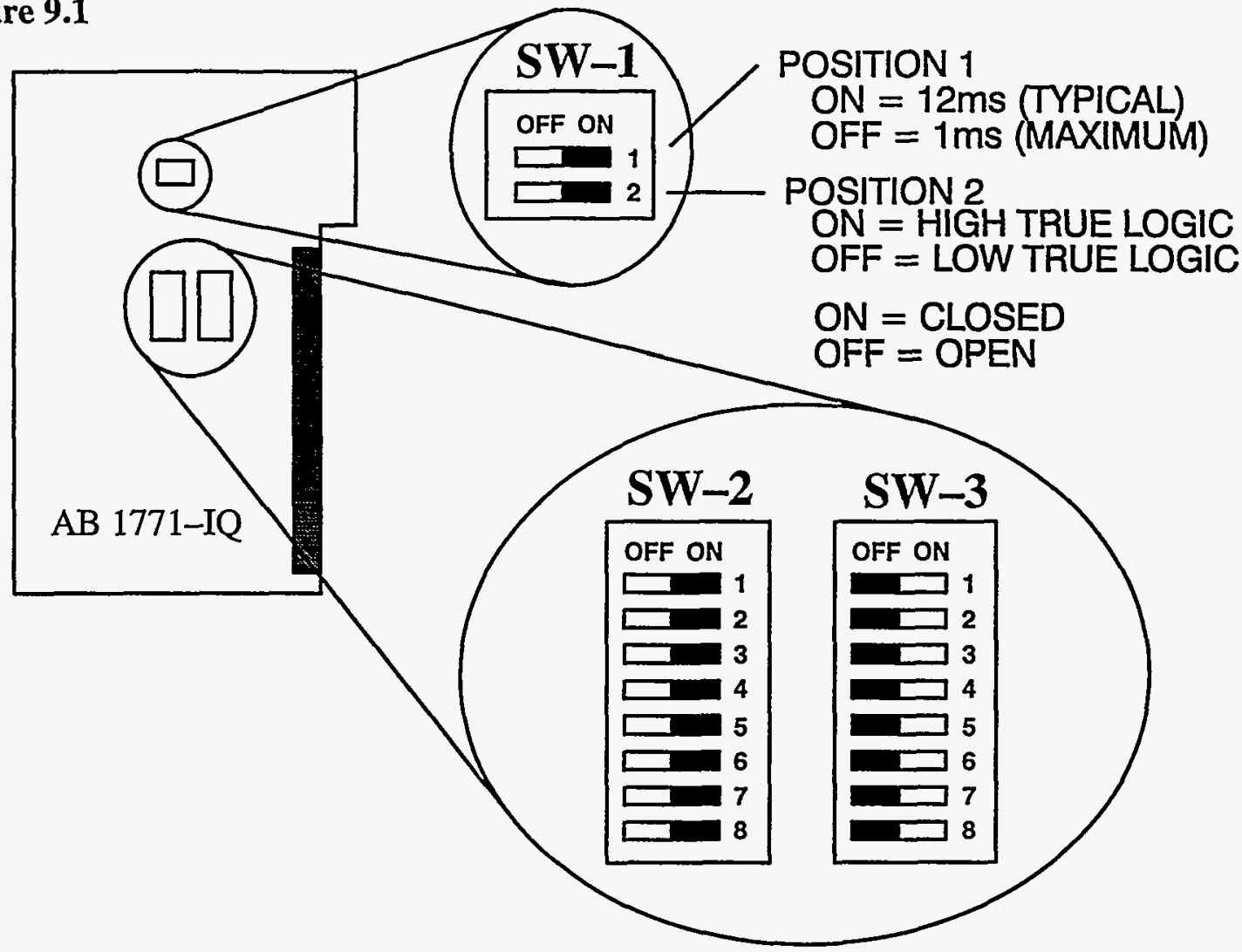

\subsubsection{Module Keying}

The Allen Bradley Universal I/O chassis have the ability to limit the slot access to certain modules by the implementation of a keying system. Modules are slotted in two places at the edge of the circuit board. The position of the keying bands on the backplane connector of the I/O chassis must correspond to these slots. To key a slot for use by the 1771-IQ Contact Output only, place the keying bands between 6 and 8 and between 24 and 26 on the I/O chassis backplane connector.

\subsubsection{Module Insertion}

Before a module is inserted into the Universal I/O Chassis, be sure that the power to the chassis is shut off. This can be done without shutting off the IOC that the Universal I/O Chassis is connected to, and without removing the subnet communication link. To insert the module, place it in the plastic tracks on the top and bottom of the Universal I/O Chassis. Slide the module into the Universal I/O Chassis until the module comes in contact with the backplane connector. Do not force the module in, instead apply firm and even pressure on the módule to seat it properly on the backplane connector. Snap the chassis latch over the top of the module and connect the wiring arm to the module. The Universal I/O Chassis should begin communicating with the host IOC when power is reapplied, no rebooting of the IOC will have to be done. 


\subsection{1-IQ DC Selectable Input Module Wiring Connection}

Connecting field wiring to the 1771-IQ is accomplished through the use of the wiring arm. Signals should be connected to the screw terminals of the wiring arm, as detailed in figure 9.2 , and the wiring arm should be connected to the front tab connector on the 1771-IQ. When shielded cable is used and grounding of the shield is desired, it is recommended that the connection be made at one of the $\mathrm{I} / \mathrm{O}$ chassis mounting bolts. To prevent ground loops only one end of the cable shield should be grounded.

Figure 9.2

DC Input Connection

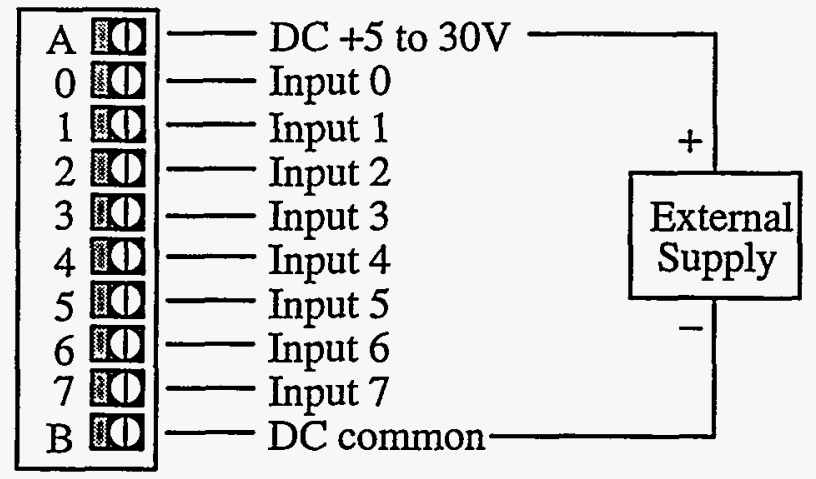

\subsection{1-IQ DC Selectable Input Module Use}

The front panel of the 1771-IQ contains eight red status indicators. Each of these indicators corresponds to a single circuit within the module. When the input to a specific circuit is TRUE (whether the module is selected for HIGH TRUE or LOW TRUE logic), its corresponding status indicator will illuminate. The top LED will indicate the status of signal 0 , while the bottom LED will indicate the status of signal 7. 


\section{CHAPTER 10 Allen-Bradley 1771-OW Contact Output Module}

\subsection{1-OW Contact Output Module}

The 1771-OW controls eight relay contact outputs by sending the proper 8-bit data value to the module. The relay contacts can be set for either N.O. (normally-open) or N.C. (normally-closed) configurations. The 1771-OW does not contain any surge limiting circuitry and is recommended to be used in resistive loads only, not inductive or capacitive loads. The contacts are rated at $24-138 \mathrm{~V} \mathrm{AC} \mathrm{rms,} \mathrm{and} 24-125 \mathrm{~V} \mathrm{DC}, 1 \mathrm{~A}$ per channel. The minimum contact load is $10 \mathrm{~mA}$ at $24 \mathrm{~V} \mathrm{DC}$ and $10 \mathrm{~mA}$ at $24 \mathrm{~V} \mathrm{AC}$.

\subsection{1-OW Contact Output Module Strapping}

Remove the module's left hand cover plate (the one without the labels). Observe the location of the configuration jumpers in figure 10.1, and note the location of the individual channels.

Figure 10.1

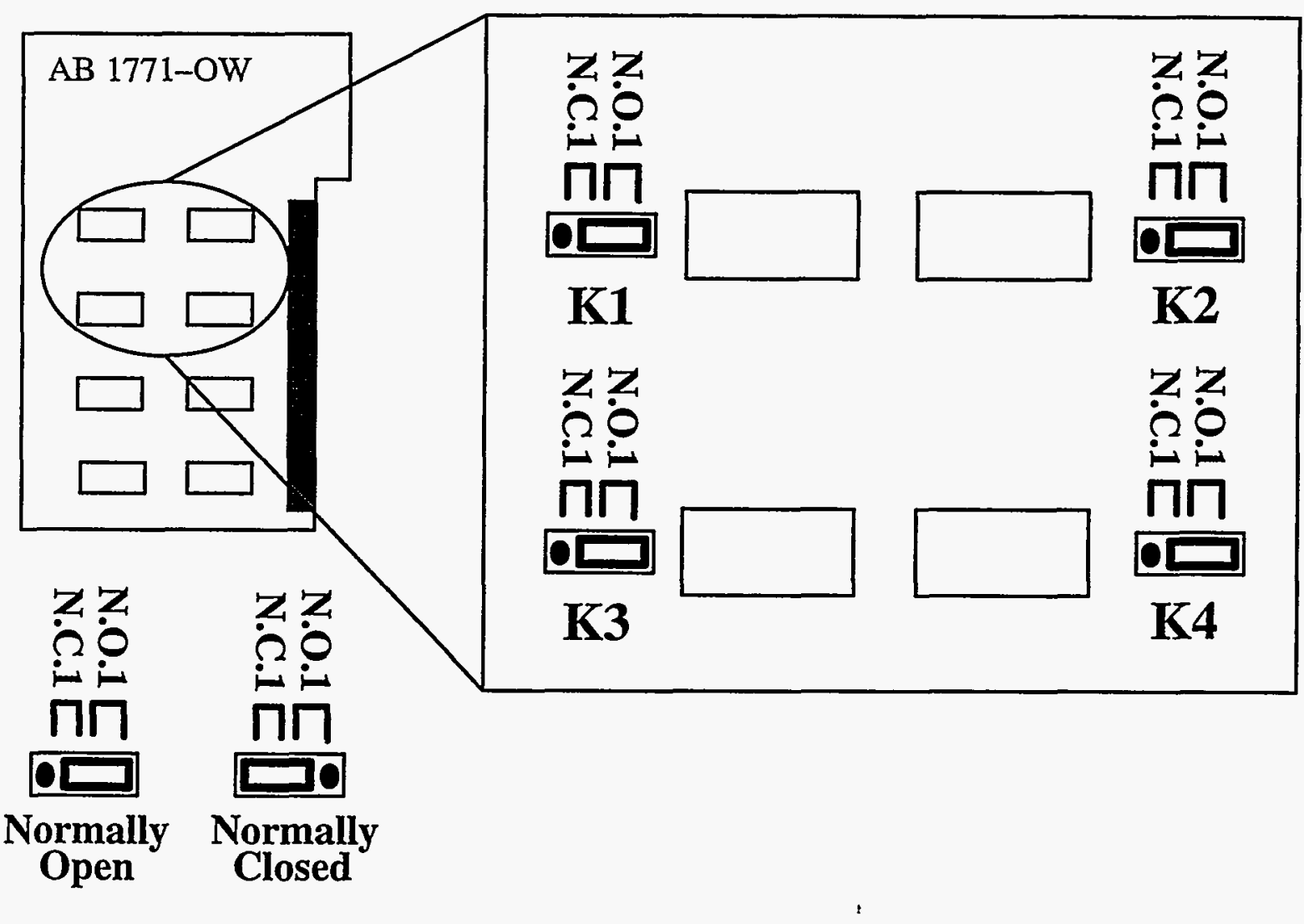

All outputs are individually selectable for either N.O. or N.C. operation. To select N.O. or N.C. settings refer to figure 10.1 for strap location and settings. $\mathrm{K} 1$ corresponds to signal 0 and $\mathrm{K} 8$ corresponds to signal 7. Note that figure 10.1 shows only the top four jumper points. 


\subsection{1-OW Contact Output Module Installation}

\subsubsection{Power Requirements}

The Allen-Bradley 1771-OW Contact Output Module may be installed in any Allen-Bradley Universal I/O Chassis, 1771-A1B, 1771-A2B, 1771-A3B, or 1771-A4B. Before Installation, calculate the power requirements of the modules currently in the chassis. Add to that $700 \mathrm{~mA} @ 5 \mathrm{~V} \mathrm{DC}$, the current required by the $1771-\mathrm{OW}$. Check to be sure that this combined current requirement does not exceed the current driving ability of the chassis power supply.

\subsubsection{Module Location in the I/O Chassis}

The 1771-OW may be place in any slot of the I/O chassis with the exception of of the extreme left slot. This slot is occupied by the Remote I/O Adapter Module. It is suggested that analog input modules and low voltage DC modules be placed away from AC modules or high voltage DC modules to minimize electrical noise interference.

\subsubsection{Module Keying}

The Allen Bradley Universal I/O chassis have the ability to limit the slot access to certain modules by the implementation of a keying system. Modules are slotted in two places at the edge of the circuit board. The position of the keying bands on the backplane connector of the I/O chassis must correspond to these slots. To key a slot for use by the 1771-OW Contact Output only, place the keying bands between 6 and 8 and between 16 and 18 on the I/O chassis backplane connector.

\subsubsection{Module Insertion}

Before a module is inserted into the Universal I/O Chassis, be sure that the power to the chassis is shut off. This can be done without shutting off the IOC that the Universal I/O Chassis is connected to, and without removing the subnet communication link. To insert the module, place it in the plastic tracks on the top and bottom of the Universal I/O Chassis. Slide the module into the Universal I/O Chassis until the module comes in contact with the backplane connector. Do not force the module in, instead apply firm and even pressure on the module to seat it properly on the backplane connector. Snap the chassis latch over the top of the module and connect the wiring arm to the module. The Universal I/O Chassis should begin communicating with the host IOC when power is reapplied, no rebooting of the IOC will have to be done.

\subsection{1-OW Contact Output Module Wiring Connection}

Connecting field wiring to the 1771-OW is accomplished through the use of the wiring arm. Signals should be connected to the screw terminals on the wiring arm, as detailed in figure 10.2 , and the wiring arm should be connected to the front tab connector on the 1771-OW. Note: The Contacts in figure 10.2 show the factory default configuration. Each relay can be configured for either N.O. or N.C. operation. Refer to section 10.2 to properly configure each relay individually. When shielded cable is used and grounding of the shield is desired, it is recommended that the connection be made at one of the $\mathrm{I} / \mathrm{O}$ chassis mounting bolts. To prevent ground loops only one end of the cable shield should be grounded. 
Figure 10.2 Contact Output Connections

\begin{tabular}{|c|c|}
\hline 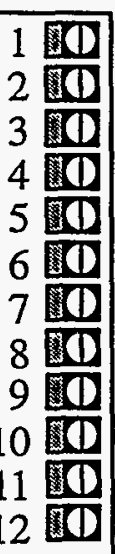 & $\begin{array}{l}\text { ut } 0 \text { (N.O.) } \\
\text { mon } \\
\text { ut } 1 \text { (N.O.) } \\
\text { ut } 2 \text { (N.O.) } \\
\text { mon }\end{array}$ \\
\hline
\end{tabular}

\subsection{1-OW Contact Output Module Use}

The front panel of the 1771-OW contains eight red LED indicators. Each indicator is lit when its corresponding relay is energized. The Top LED will indicate the status of signal 0 , while the bottom LED will indicate the status of signal 7. 


\section{CHAPTER 11 Allen-Bradley 1771-IBD DC (10-30V) Input Module}

\subsection{1-IBD DC (10-30V) Input Module}

The 1771-IBD DC (10-30V) Input Module accepts DC voltage levels on 16 inputs and converts these signals to logic levels. The minimum input current rating is $4 \mathrm{~mA}$ at $10 \mathrm{~V} \mathrm{DC}$ and $12 \mathrm{~mA}$ at $30 \mathrm{~V} \mathrm{DC}$. The minimum on state voltage is $10 \mathrm{VDC}$. The Maximum off state current is $2.4 \mathrm{~mA}$, and the maximum off state voltage is $6 \mathrm{~V} \mathrm{DC}$. The input impedance of the module is $2.5 \mathrm{~K}$ ohms maximum per channel.

\subsection{1-IBD DC (10-30V) Input Module Strapping}

The 1771-IBDDC (10-30V) Input Module has a fault mode which may be configured. This fault mode is independent of the last state switch on the Universal I/O Chassis backplane, and will place the inputs of the module in the corresponding state if a fault is detected. To configure the fault mode jumper, locate the jumper at the top edge of the module circuit board as it appears in figure 11.1. Configure the 2 position jumper on the middle and LS pin of the three pin header for last state fault mode. Configure the two position jumper on the middle and RESET pin of the three pin header for reset fault mode.

Figure 11.1

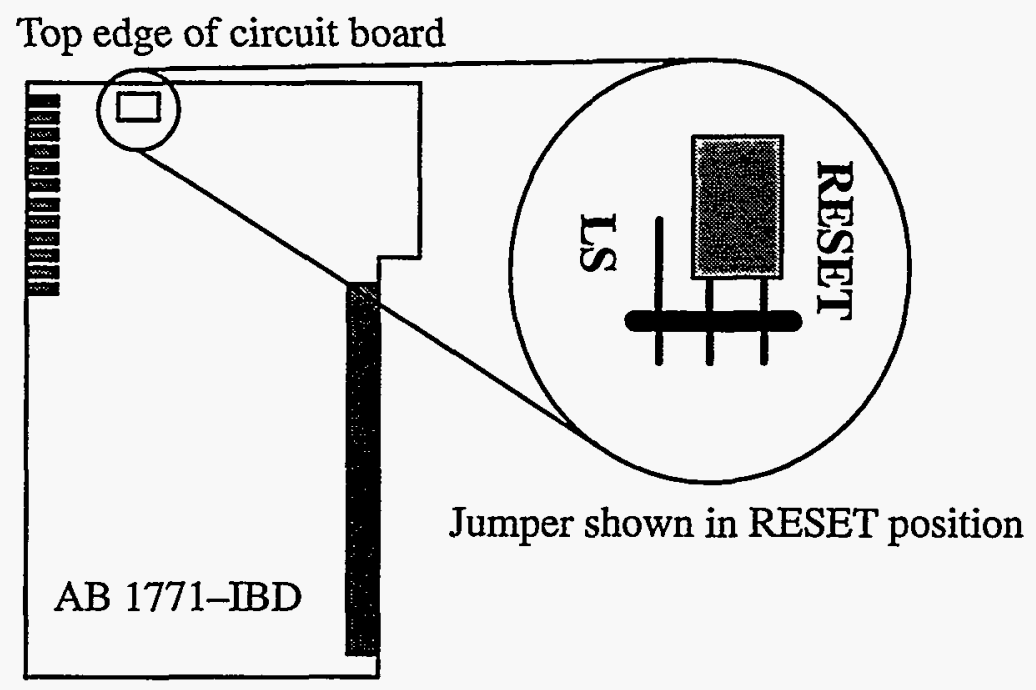

\subsection{1-IBD DC (10-30V) Input Module Installation}

\subsubsection{Power Requirements}

The Allen-Bradley 1771-IBD may be installed in any Allen-Bradley Universal I/O Chassis, 1771-A1B, 1771-A2B, 1771-A3B, or 1771-A4B. Before Installation, calculate the power requirements of the modules currently in the chassis. Add to that $250 \mathrm{~mA} @ 5 \mathrm{~V} \mathrm{DC}$, the current required by the $1771-\mathrm{BBD}$. Check to be sure that this combined current requirement does not exceed the current driving ability of the chassis power supply. 


\subsubsection{Module Location in the $\mathrm{I} / \mathrm{O}$ Chassis}

The 1771-IBD may be placed in any slot of the I/O chassis with the exception of of the extreme left slot. This slot is occupied by the Remote I/O Adapter Module. It is suggested that analog input modules and low voltage $\mathrm{DC}$ modules be placed away from $\mathrm{AC}$ modules or high voltage DC modules to minimize electrical noise interference.

The 1771-IBD has an additional restriction. EPICS software reads and writes the AllenBradly chassis in Two-slot addressing mode. A module group is considered to contain two Allen-Bradly slots. The first module group address is located at slot 0 and 1 . The second is slot 2 and 3 and so on. When using a 16-bit input module in a two-slot addressing mode, the input module must always be inserted into an even number slot (left-hand side of the module group). A complementary output module (8-bit or 16-bit module) may be inserted into an odd number slot (right-hand side of the module group) completing the module group. If no complementary module is used then that slot must remain empty.

\subsubsection{Module Keying}

The Allen Bradley Universal V/O chassis have the ability to limit the slot access to certain modules by the implementation of a keying system. Modules are slotted in two places at the edge of the circuit board. The position of the keying bands on the backplane connector of the I/O chassis must correspond to these slots. To key a slot for use by the 1771-IQ Contact Output only, place the keying bands between 10 and 12 and between 16 and 18 on the $/ / O$ chassis backplane connector.

\subsubsection{Module Insertion}

Before a module is inserted into the Universal I/O Chassis, be sure that the power to the chassis is shut off. This can be done without shutting off the IOC that the Universal I/O Chassis is connected to, and without removing the subnet communication link. To insert the module, place it in the plastic tracks on the top and bottom of the Universal I/O Chassis. Slide the module into the Universal I/O Chassis until the module comes in contact with the backplane connector. Do not force the module in, instead apply firm and even pressure on the module to seat it properly on the backplane connector. Snap the chassis latch over the top of the module and connect the wiring arm to the module. The Universal I/O Chassis should begin communicating with the host IOC when power is reapplied, no rebooting of the IOC will have to be done.

\subsection{1-IBD DC (10-30V) Input Module Wiring Connection}

Connecting field wiring to the 1771-IBD is accomplished through the use of the wiring arm. Signals should be connected to the screw terminals of the wiring arm, as detailed in figure 11.2 , and the wiring arm should be connected to the front tab connector on the 1771-IBD. Note that on the wiring arm the inputs are labeled $00-17$ (octal). When shielded cable is used and grounding of the shield is desired, it is recommended that the connection be made at one of the I/O chassis mounting bolts. To prevent ground loops only one end of the cable shield should be grounded. 
Figure 11.2

\begin{tabular}{|c|c|}
\hline 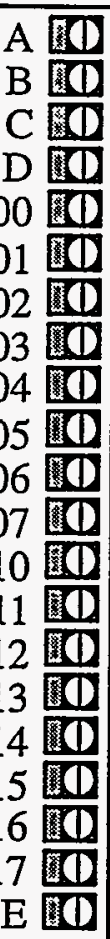 & \\
\hline
\end{tabular}

\subsection{1-IBD DC (10-30V) Input Module Use}

The front panel on the 1771-IBD contains 17 LED indicators. The top green LED indicator labeled ACTIVE indicates the module is connected to +5 volts and operating normally. The next 16 red LED indicators, labeled 00 through 17 (octal), will indicate if an input is true. The indicator will be illuminated if the input is true (there is voltage at the terminal) and out if the input is false (there is no voltage at the terminal). 


\section{CHAPTER 12 Allen-Bradley 1771-OBD DC (10-60V) Output Module}

\subsection{1-OBD DC (10-60V) Output Module}

The 1771-IBD DC (10-60V) Output Module produces a DC voltage level on any combination of 16 outputs. The voltage level output is determined by a user supplied power supply. The maximum output current is $2 \mathrm{~A}$ per output, not to exceed $8 \mathrm{~A}$ per module.

\subsection{1-OBD DC (10-60V) Output Module Strapping}

The 1771-OBD DC (10-60V) Output Module has a fault mode which may be configured. This fault mode is independent of the last state switch on the Universal I/O Chassis backplane, and will place the outputs of the module in the corresponding state if a fault is detected. To configure the fault mode jumper, locate the jumper at the bottom edge of the module circuit board as it appears in figure 12.1. Configure the 2 position jumper on the middle and LS pin of the three pin header for last state fault mode. Configure the two position jumper on the middle and RESET pin of the three pin header for reset fault mode.

\section{Figure 12.1}

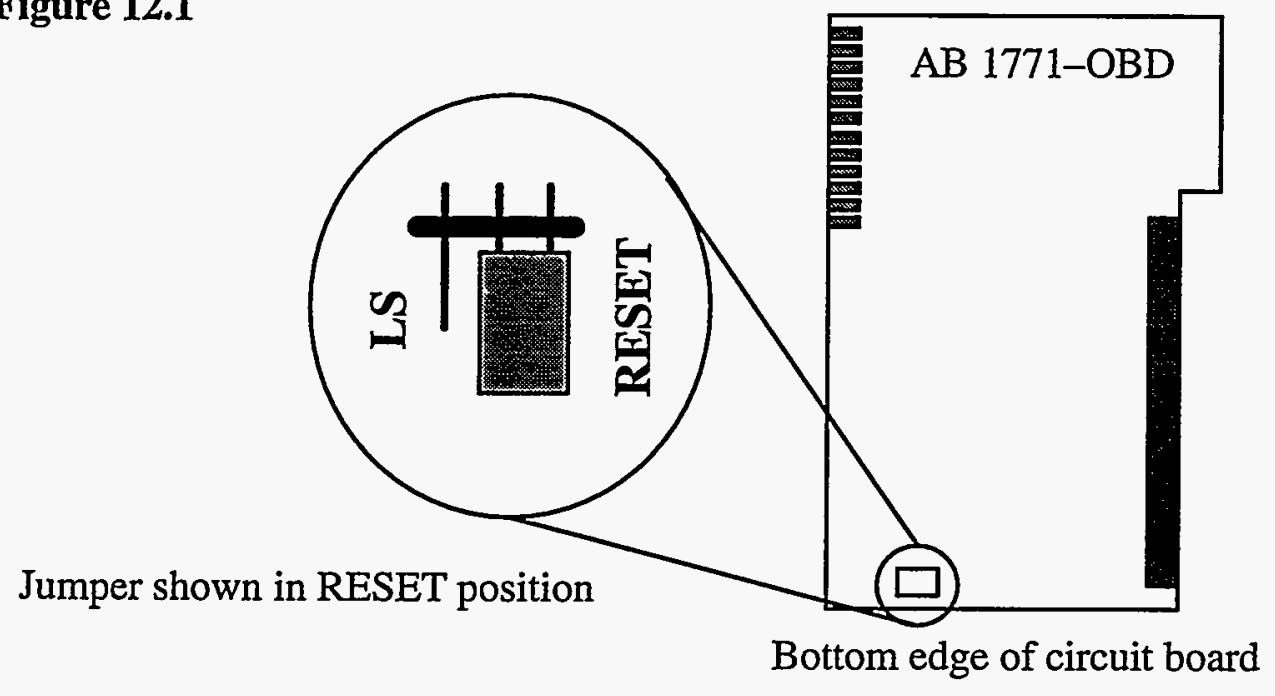

\subsection{1-OBD DC (10-60V) Output Module Installation}

\subsubsection{Power Requirements}

The Allen-Bradley 1771-OBD may be installed in any Allen-Bradley Universal I/O Chassis, 1771-A1B, 1771-A2B, 1771-A3B, or 1771-A4B. Before Installation, calculate the power requirements of the modules currently in the chassis. Add to that $400 \mathrm{~mA} @ 5 \mathrm{VDC}$, the current required by the $1771-\mathrm{IBD}$. Check to be sure that this combined current requirement does not exceed the current driving ability of the chassis power supply. 


\subsubsection{Module Location in the I/O Chassis}

The 1771-OBD may be placed in any slot of the I/O chassis with the exception of of the extreme left slot. This slot is occupied by the Remote I/O Adapter module. It is suggested that analog input modules and low voltage DC modules be placed away from AC modules or high voltage DC modules to minimize electrical noise interference.

The 1771-OBD has an additional restriction. EPICS software reads and writes the AllenBradly chassis in Two-slot addressing mode. A module group is considered to contain two Allen-Bradly slots. The first module group address is located at slot 0 and 1 . The second is slot 2 and 3 and so on. When using a 16-bit output module in a two-slot addressing mode, the output module must always be inserted into an odd number slot (right-hand side of the module group). A complementary input module (8-bit or 16-bit module) may be inserted into an even number (left-hand side of the module group) slot completing the module group. If no complementary module is used then that slot must remain empty.

\subsubsection{Module Keying}

The Allen Bradley Universal I/O chassis have the ability to limit the slot access to certain modules by the implementation of a keying system. Modules are slotted in two places at the edge of the circuit board. The position of the keying bands on the backplane connector of the I/O chassis must correspond to these slots. To key a slot for use by the 1771-IQ Contact Output only, place the keying bands between 10 and 12 and between 22 and 24 on the I/O chassis backplane connector.

\subsubsection{Module Insertion}

Before a module is inserted into the Universal I/O Chassis, be sure that the power to the chassis is shut off. This can be done without shutting off the IOC that the Universal I/O Chassis is connected to, and without removing the subnet communication link. To insert the module, place it in the plastic tracks on the top and bottom of the Universal I/O Chassis. Slide the module into the Universal I/O Chassis until the module comes in contact with the backplane connector. Do not force the module in, instead apply firm and even pressure on the module to seat it properly on the backplane connector. Snap the chassis latch over the top of the module and connect the wiring arm to the module. The Universal I/O Chassis should begin communicating with the host IOC when power is reapplied, no rebooting of the IOC will have to be done.

\subsection{1-OBD DC (10-60V) Output Module Wiring Connection}

Connecting field wiring to the 1771-OBD is accomplished through the use of the wiring arm. Signals should be connected to the screw terminals of the wiring arm, as detailed in figure 12.2 , and the wiring arm should be connected to the front tab connector on the 1771-OBD. Note that on the wiring arm the outputs are labeled $00-17$ (octal). When shielded cable is used and grounding of the shield is desired, it is recommended that the connection be made at one of the I/O chassis mounting bolts. To prevent ground loops only one end of the cable shield should be grounded. 
Figure 12.2

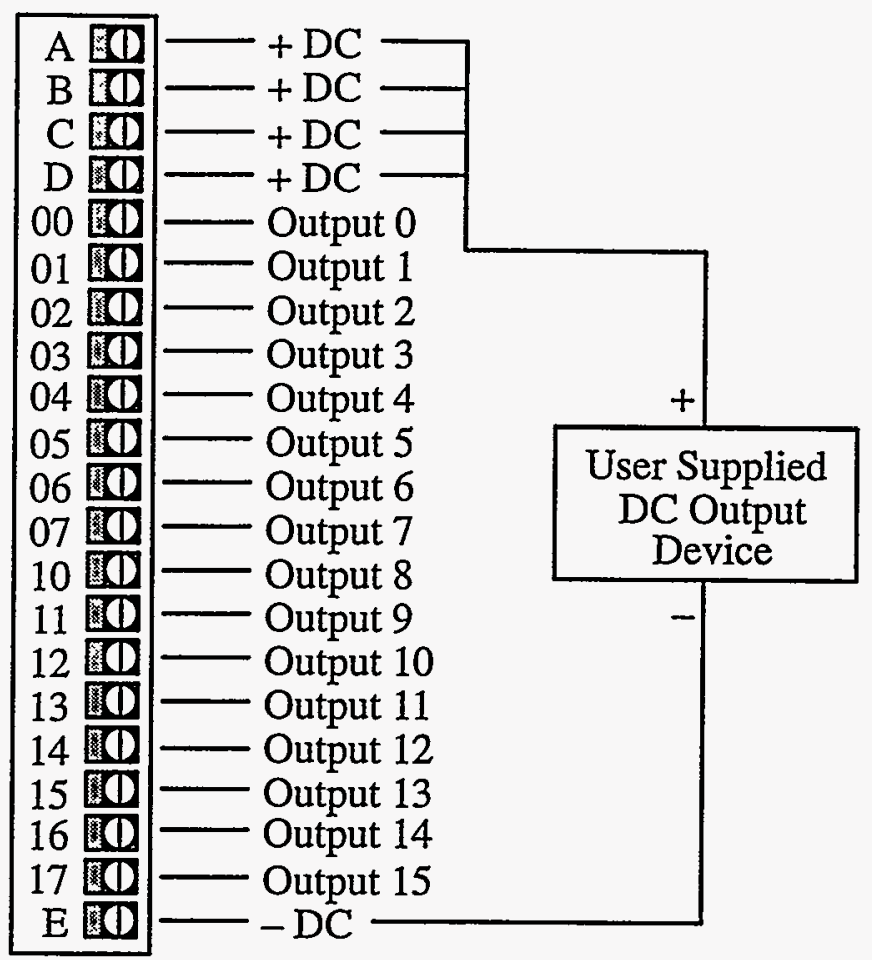

\subsection{1-OBD DC (10-60V) Output Module Use}

The front panel on the 1771-OBD contains 18 LED indicators. The top green LED indicator labeled ACTIVE indicates the module is connected to +5 volts and operating normally. The next 16 red LED indicators, labeled 00 through 17 (octal), will indicate if an output is true. The indicator will be illuminated if the output is true (there is voltage at the terminal) and out if the output is false (there is no voltage at the terminal). There is also a red LED FUSE indicator. This will be illuminated if the on-board output protection fuse is blown. 


\section{CHAPTER 13 Allen-Bradley 1771-IXE Thermocouple / Millivolt Input Module}

\subsection{1-IXE Thermocouple / Millivolt Input Module}

The 1771-LXE senses up to 8 differential analog inputs and converts them to a proportional 12 bit binary value. The 1771-IXE will support $E, J, K, T, R$, and $S$ thermocouples, as will as a range of $+1-100 \mathrm{mV}$. These ranges are selectable in the EPICS database configuration software.

\subsection{1-IXE Thermocouple / Millivolt Input Module Strapping}

No strapping of the 1771-IXE Module is required.

\subsection{1-IXE Thermocouple / Millivolt Input Module Installation}

\subsubsection{Power Requirements}

The Allen-Bradley 1771-IXE Analog Input Module may be installed in any Allen-Bradley Universal I/O Chassis, 1771-A1B, 1771-A2B, 1771-A3B, or 1771-A4B. Before Installation, calculate the power requirements of the modules currently in the chassis. Add to that 1.2A @ 5V DC, the current required by the 1771-IFE. Check to be sure that this combined current requirement does not exceed the current driving ability of the chassis power supply.

\subsubsection{Module Location in the I/O Chassis}

The 1771-IFE may be place in any slot of the I/O chassis with the exception of of the extreme left slot. This slot is occupied by the Remote I/O Adapter Module. It is suggested that analog input modules and low voltage DC modules be placed away from AC modules or high voltage DC modules to minimize electrical noise interference.

\subsubsection{Module Keying}

The Allen Bradley Universal I/O chassis have the ability to limit the slot access to certain modules by the implementation of a keying system. Modules are slotted in two places at the edge of the circuit board. The position of the keying bands on the backplane connector of the I/O chassis must correspond to these slots. To key a slot for use by the 1771-IFE Analog Input only, place the keying bands between 20 and 22 and between 24 and 26 on the I/O chassis backplane connector.

\subsubsection{Module Insertion}

Before a module is inserted into the Universal I/O Chassis, be sure that the power to the chassis is shut off. This can be done without shutting off the IOC that the Universal I/O Chassis is connected to, and without removing the subnet communication link. To insert the module, place it in the plastic tracks on the top and bottom of the Universal I/O Chassis. Slide the module into the Universal I/O Chassis until the module comes in contact with the backplane connector. Do not force the module in, instead apply firm and even pressure on the module 
to seat it properly on the backplane connector. Snap the chassis latch over the top of the module and connect the wiring arm to the module. The Universal I/O Chassis should begin communicating with the host IOC when power is reapplied, no rebooting of the IOC will have to be done.

\subsection{1-IXE Thermocouple / Millivolt Input Module Wiring Connection}

Connection of analog signals to the 1771-LXE is accomplished through the use of the wiring arm. Signals should be connected to the screw terminals on the wiring arm, as detailed in figure 13.1, and the wiring arm should be connected to the front tab connector on the 1771-IXE. The recommend maximum cable length for thermocouple signals is $1000 \mathrm{ft}$ for thermocouple extension wire of 18 or 22 gauge. This is based on the fact that the 1771-IXE module compensates for lead resistance up to $2000 \mathrm{ohms}$. If this lead resistance must be exceeded, refer to the thermocouple manufacturer's specifications and instructions for compensation. When shielded cable is used and grounding of the shield is desired, it is recommended that the connection be made at one of the I/O chassis mounting bolts. To prevent ground loops only one end of the cable shield should be grounded. Note also that all unused inputs should be short circuited.

Figure 13.1
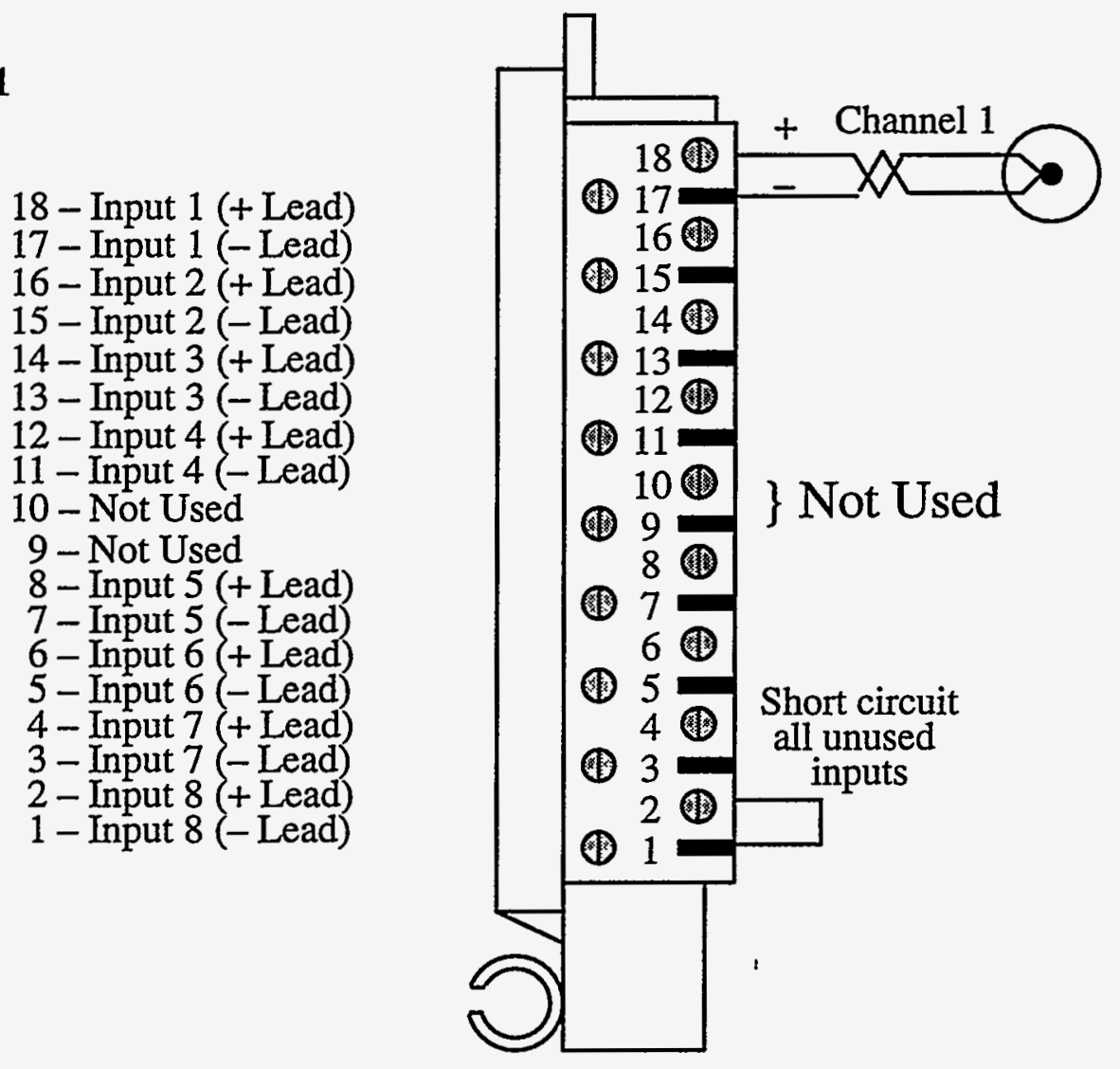


\subsection{1-IXE Thermocouple / Millivolt Input Module Use}

The front panel of the 1771-IFE contains a green RUN and a red FAULT LED indicator. At power up an initial module self-check occurs. If there is no fault the red indicator will turn off. The green indicator will flash until the processor communicates successfully with the module. 


\section{CHAPTER 14 Allen-Bradley 2705 RediPANEL Push Button Module}

\subsection{RediPANEL Push Button Module}

The Allen-Bradley 2705 RediPANEL Push Button Module combines the functions of standard push buttons and indicator lamps, an Allen Bradley Chassis with binary input, and binary output modules, and a 1771-ASB Remote I/O Adapter Module. The RediPANEL provides 16 discrete binary inputs in the form of push buttons, and 16 discrete binary outputs in the form of indicator lamps behind the buttons. Like the 1771-ASB Remote I/O Adapter Module, the RediPANEL acts as a slave in an Allen Bradley subnet in an EPICS control system. The RediPANELs are linked via subnet connection to other RediPANELs and Remote I/O Adapters, and back to a VMEbus I/O scanner. They correspond to the ADAPTER number when configuring an Allen-Bradley subnet. An Allen-Bradley / EPICS subnet allows for up to 8 adapters to be located on one Allen-Bradley subnet link.

\subsection{RediPANEL Push Button Module Configuration}

Refer to figure 14.1 for the following instructions.

Figure 14.1

Switches should be visible through a hole near the upper right hand corner of the back of the RediPANEL module.

\subsubsection{Setting the Module Switches}

SW1 is the Address Switch Assembly for the RediPANEL modules. Switches $1-6$ select the Universal I/O Chassis adapter number. Observe figure 14.2 for the proper address settings, when the switches are closed $(\mathrm{ON})$ this corresponds to a binary 0 in the adapter address, and when the switches are open (OFF) this corresponds to a binary 1 in the adapter address. Note that switches $1-3$ must always remain in their closed (ON) positions as the EPICS control system only uses adapter addresses $0-7$. 
Figure 14.2

\begin{tabular}{|c|c|c|c|}
\hline I/O Adapter & \multicolumn{3}{|c|}{ Switch Number } \\
Number & 4 & 5 & 6 \\
\hline 1 & On & On & On \\
\hline 2 & On & On & Off \\
\hline 3 & On & Off & On \\
\hline 4 & On & Off & Off \\
\hline 5 & Off & On & On \\
\hline 6 & Off & On & Off \\
\hline 7 & Off & Off & On \\
\hline
\end{tabular}

Switches 7 and 8 should remain in the closed (ON) position as this will place the Remote I/O adapter in the 1st I/O group number 0, used in the EPICS control system.

SW2 sets the baud rate and other configurations. Switch number 1 should be closed (ON), this sets the baud rate at $57.6 \mathrm{~K}$ baud and allows for a link distance of $10,000 \mathrm{ft}$ over shielded, twisted pair cable. Switches 2 and 3 respectively control the the ability to make the lamp indicators appear steady or flashing, see section 14.5 .1 for more information on this. Switch number 2 should be open (OFF) to disable the steady lamp setting, and closed (ON) to enable the steady lamp setting. Switch number 3 should be open (OFF) to disable the flashing lamp setting, and closed (ON) to enable the flashing lamp setting. Switch number 4 is for the push buttons, it should be set open (OFF) to disable the push buttons, and closed (ON) to enable the push buttons. Switch number 5 controls the switch fault action. If the switch is set closed (ON), all push button operations will cease when a fault is detected using the Push-To-Test button, communication will halt, and the FAULT LED will illuminate. If the switch is set open (OFF), faulted contacts will be forced to the released state, all other switches will operate normally.

Switch number 6 should be open (OFF) as it is not used. Switch 7 should be open (OFF) to disable the handshake bit. Switch 8 controls the last state function. This switch should be closed (ON) to enable the last state function. In this mode, when communication is lost and the COMM LED is off, any output signals that were on will remain in the same state once communication is restored. If switch 8 is set open (OFF), the module will turn off any output signals that were on when communication was lost. A summary of switch positions is available in figure 14.3.

\subsection{RediPANEL Push Button Module Installation}

\subsubsection{Power Requirements}

The RediPANEL is wired via a three pin terminal block to a standard three wire AC power cord. The three pin terminal block plugs into the back of the rediPANEl and accepts $90-$ $264 \mathrm{~V} \mathrm{AC}$ ranging from $47-63 \mathrm{~Hz}$. When all of the lamps are activated the internal DC power supply provides a maximum of $360 \mathrm{~mA}$ of current. If all of the lamps are de-activated, the current draw on the internal DC supply is $190 \mathrm{~mA}$. 
Figure 14.3

\begin{tabular}{|c|c|c|c|c|c|c|c|c|c|c|c|c|c|c|}
\hline \multicolumn{7}{|c|}{ S1 Switch Number } & \multicolumn{7}{|c|}{ S2 Switch Number } \\
\hline 1 & 2 & 3 & 4 & 5 & 7 & 7 & 1 & 2 & 3 & 4 & 5 & 7 & 8 \\
\hline On & On & On & Figure 14.2 & On & On & On & X & X & X & X & Off & Off & X \\
\hline
\end{tabular}

On $=$ Closed

Off $=$ Open

$\mathrm{X}=$ Refer to written instructions above

\subsubsection{Mechanical}

In order to protect the RediPANEL against heat, soot, moisture and other forms of contamination, an enclosure is required. When choosing an enclosure for the RediPANEL, it is advised to follow the standards developed by the National Electrical Manufacturers Association (NEMA). Refer to NEMA Standard \# 250, "Enclosures for Electrical Equipment" to find a suitable enclosure.

Each RediPANEL comes with two mounting brackets and a cut-out template to simplify installation. The panels can be mounted either horizontally or vertically. Mounting multiple panels horizontally requires at least one inch of spacing around the mounting flange, vertical spacing should be at least 6 inches between cut-outs. In both cases, the depth of the enclosure should be at least 8 inches.

\subsection{RediPANEL Push Button Module Wiring Connection}

Figure 14.4 details the wiring connections to the RediPANEL mating connector. After the wires are inserted into the connector as detailed in figure 14.4, the connector can be plugged into the receptacle located near the lower right hand corner of the back of the RediPANEL. The AC power must also be connected as mentioned in 14.3.1.

Figure 14.4

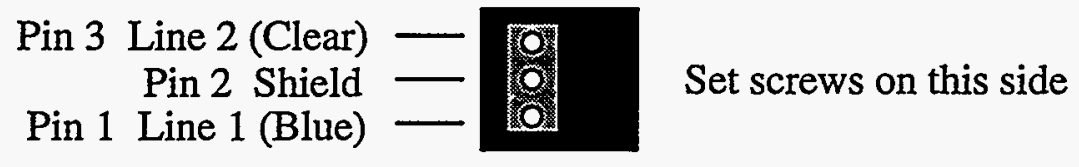

\subsection{RediPANEL Push Button Module Module Use}

\subsubsection{Mapping to EPICS}

Mapping the the buttons to an EPICS control system is quite simple. There are 16 buttons, and 16 lamp indicators, divided into 4 "cards". The first 8 buttons are represented as CARD 0 , binary inputs SIGNALS $0-7$, and the second 8 buttons are represented as CARD 1, binary inputs SIGNALS $0-7$. Likewise, for steady lamp operation, the first 8 lamp indicators are 
represented as CARD 0, binary outputs SIGNALS $0-7$, and the second 8 lamp indicators are represented as CARD 1, binary outputs SIGNALS $0-7$. For flashing lamp operation, the first 8 buttons are still represented as CARD 0, binary inputs SIGNALS $0-7$, and the second 8 buttons are represented as CARD 1, binary inputs SIGNALS $0-7$. However, the first 8 lamp indicators are represented as CARD 2, binary outputs SIGNALS $0-7$, and the second 8 lamp indicators are represented as CARD 3, binary outputs SIGNALS 0-7. A map of the RediPANEL buttons, and indicators is shown in figure 14.5. Keep in mind that the for steady lamp operation, both the button and the lamp indicator associated with a location on the RediPANEL share the same CARD and SIGNAL address, however, the button is discerned as a binary input, and the lamp indicator is discerned as a binary output.

Figure 14.5

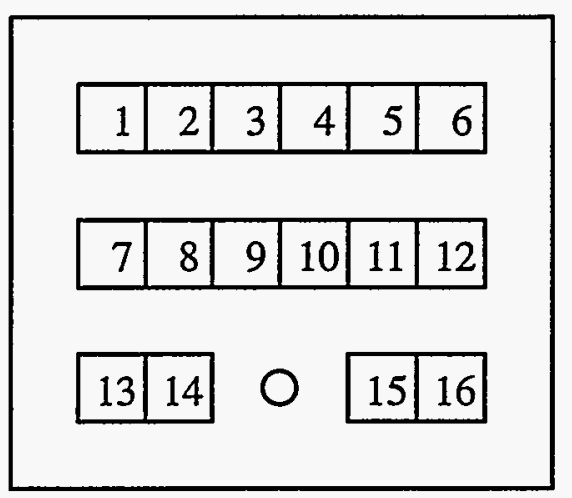

\author{
Buttons: \\ Location $1-8=$ CARD 0, SIGNALS $0-7$ \\ Location $9-16=$ CARD 1 , SIGNALS $0-7$ \\ Indicator Lamps: \\ Steady Lamps: \\ Location $1-8=$ CARD 0, SIGNALS $0-7$ \\ Location $9-16=$ CARD 1 , SIGNALS $0-7$ \\ Flashing Lamps: \\ Location $1-8=$ CARD 2, SIGNALS $0-7$ \\ Location $9-16=$ CARD 3, SIGNALS $0-7$
}

It may also be helpful to note that the EPICS binary input records for the push buttons may be set to I/O Interrupt Scan. The record will be scanned on a change of state of the push buttons as opposed to a "time" scan where one is forced to scan at a fast rate in order to "catch" the pressing of a button.

\subsubsection{Diagnostic Indicators}

In the upper right hand corner of the RediPANEL there is a green COMM LED indicator, and a red FAULT LED indicator. The possible combinations of indicator actions are listed in figure 14.6.

\subsubsection{LED and Lamp Test}

To test the indicator lamps and the LED indicators press the white round button labeled TEST on the bottom of the panel. When a test cycle is executed, all of the indicator lamps and LEDs will first go on for one second, then go off for two seconds, then return to the state they were in before the TEST button was pressed. 


\section{Figure 14.6}

\begin{tabular}{|c|c|l|}
\hline Lamp & Action & \multicolumn{1}{|c|}{ Possible Cause } \\
\hline COMM & Off & RediPANEL not communicating, check power and link \\
\hline COMM & On & RediPANEL communicating properly, no faults detected \\
\hline COMM & Blinking & Communication with the RediPANEL not yet established \\
\hline FAULT & Off & RediPANEL operating properly, no faults detected \\
\hline FAULT & On & Fault detected, power cycle the RediPANEL \\
\hline FAULT & Blinking & DIP switch fault, re-configure DIP switches properly \\
\hline
\end{tabular}

